\title{
LA UNIÓN EUROPEA ANTE EL DERECHO DE ASILO: A PROPÓSITO DE LA SENTENCIA COMISIÓN/HUNGRÍA (ACOGIDA DE SOLICITANTES DE PROTECCIÓN INTERNACIONAL)
}

JAUME FERRER LLORET ${ }^{1}$

jaume.ferrer@ua.es

Cómo citar/Citation

Ferrer Lloret, J. (2021).

La Unión Europea ante el derecho de asilo: a propósito de la Sentencia Comisión/Hungría (acogida de solicitantes de protección internacional). Revista de Derecho Comunitario Europeo, 68, 25-66. doi: https://doi.org/10.18042/cepc/rdce.68.02

\section{Resumen}

La Sentencia dictada por la Gran Sala el 17 de diciembre de 2020 en Comisión/ Hungría pone en evidencia las graves carencias que afectan a la aplicación de las normas que forman el Sistema Europeo Común de Asilo (SECA). El Tribunal de Justicia (TJ) llega a la conclusión de que las autoridades húngaras han vulnerado de forma flagrante, y durante varios años, la normativa de la UE que regula las garantías y procedimientos que deben cumplir los Estados miembros para permitir que se presente una solicitud de protección internacional; para internar a los solicitantes de protección internacional; para expulsar a un nacional de un tercer país; y para permitir

1 Catedrático de Derecho Internacional Público y Relaciones Internacionales de la Universidad de Alicante. El presente trabajo se enmarca en el proyecto de investigación, concedido por el Ministerio de Ciencia e Innovación, PID2019-107311RB-I00, del que es investigador principal el autor del presente trabajo; y en las actividades de la Cátedra Jean Monnet «European Neighbourhood Policy: EU Values and Global Challenges» (599477-EPP-1-2018-ES-EPPJMO-CHAIR), de la que es titular quien suscribe este artículo. El autor agradece las observaciones que los dos evaluadores llevaron a cabo sobre este trabajo 
a los solicitantes de protección internacional que presenten un recurso con efecto suspensivo contra la decisión denegatoria de su solicitud. Aunque esta jurisprudencia del TJ merezca una valoración positiva, al mismo tiempo se debe insistir en que no se garantiza la efectiva aplicación de tales normas en favor de los miles de nacionales de terceros países, a los que las autoridades húngaras han impedido beneficiarse de las normas del SECA en el período comprendido entre 2015 y 2020. Cabe demandar que en situaciones como esta, en las que está en juego la aplicación de las normas del SECA en favor de miles de potenciales solicitantes de protección internacional, la Comisión Europea sea más diligente y resolutiva a la hora de iniciar un procedimiento por incumplimiento de conformidad con el art. 258 TFUE; y más en concreto, solicite al TJ la aplicación de medidas provisionales, con el apercibimiento de que en caso de no ser cumplidas, el Estado infractor será sancionado con una multa coercitiva.

\title{
Palabras clave
}

Tribunal de Justicia; SECA; Hungría; solicitud de protección internacional; internamiento; expulsión; efecto suspensivo de los recursos; recurso por incumplimiento; medidas provisionales; multa coercitiva.

\section{THE EUROPEAN UNION AND THE RIGHT TO ASYLUM: REGARDING THE JUDGMENT COMMISSION/HUNGARY (THE RECEPTION OF APPLICANTS FOR INTERNATIONAL PROTECTION)}

\begin{abstract}
The judgement of the Grand Chamber of December 17 2020, in Commission/ Hungary, shows the serious shortcomings that affect the application of the rules of the Common European Asylum System (CEAS). The Court of Justice (CJEU) concludes that the Hungarian authorities have flagrantly violated, for several years, the EU norms governing the guarantees and procedures that the Member States must follow to allow an application for international protection to be submitted; to detain applicants for international protection; to forced removal a third country national; and to allow applicants for international protection to file an appeal with suspensive effect against the decision to deny their application. Although this case-law of the CJEU deserves a positive assessment, at the same time it must be emphasized that it does not guarantee the effective application of its rules in favor of the thousands of third-country nationals whom the Hungarian authorities have prevented benefiting from said rules in the period from 2015 to 2020. It should be demanded that in situations like this, in which the application of the CEAS rules in favor of thousands of potential applicants for international protection is at stake, the European Commission be more diligent and decisive when initiating an action for failure to fulfil obligations of art. 258 TFEU; and more specifically, it requests the Court to apply
\end{abstract}


interim measures, with the warning that if they are not complied with, the offending State will be sanctioned with a penalty payment.

\section{Keywords}

Court of Justice; CEAS; Hungary; application for international protection; detention; forced removal; suspensive effect of appeals; action for failure to fulfil obligations; interim measures; penalty payment.

\section{L'UNION EUROPÉENNE ET LE DROIT D'ASILE: À PROPOS DE L'ARRÊT COMMISSION/HONGRIE (ACCUEIL DES DEMANDEURS DE PROTECTION INTERNATIONALE)}

\section{Résumé}

L'arrêt de la Grande Chambre du 17 décembre 2020, Commission/Hongrie, met en évidence les graves lacunes qui affectent l'application des normes du Régime d'Asile Européen Commun (RAEC). La Cour de justice conclut que les autorités hongroises ont violé de manière flagrante, pendant plusieurs années, la réglementation de l'UE régissant les garanties et les procédures que les États membres doivent suivre pour permettre l'introduction d'une demande de protection internationale; détenir les demandeurs de protection internationale; expulser un ressortissant de pays tiers; et de permettre aux demandeurs de protection internationale de déposer un recours avec effet suspensif contre la décision de rejeter leur demande. Si cette jurisprudence de la Cour de justice mérite une appréciation positive, il faut en même temps souligner qu'elle ne garantit pas l'application effective de ces normes en faveur des milliers de ressortissants de pays tiers, qui ont été empêchés de bénéficier des normes du RAEC par les autorités hongroises au cours de la période 2015-2020. Il faut exiger que dans des situations comme celle-ci, dans lequel l'application des normes du RAEC en faveur de milliers de demandeurs potentiels de protection internationale est en jeu, la Commission européenne soit plus diligente et décisive au moment de l'ouverture d'un recours en manquement de l'art. 258 TFEU; et plus précisément, qu'il demande à la Cour d'appliquer des mesures provisoires, avec l'avertissement que si elles ne sont pas respectées, l'État en infraction sera sanctionné d'une astreinte.

\section{Mots clés}

Cour de justice; RAEC; Hongrie; demande de protection internationale; détention; expulsion; effet suspensif des recours; recours en manquement; mesures provisoires; astreinte. 
I. INTRODUCCIÓN. II. HUNGRÍA IMPIDE EL ACCESO AL PROCEDIMIENTO DE PROTECCIÓN INTERNACIONAL. III. HUNGRÍA INCUMPLE LAS NORMAS SOBRE EL INTERNAMIENTO DE LOS SOLICITANTES DE PROTECCIÓN INTERNACIONAL. IV. HUNGRÍA INCUMPLE LAS GARANTÍAS Y PROCEDIMIENTOS DE RETORNO. V. EN HUNGRÍA NO EXISTEN RECURSOS CON EFECTO SUSPENSIVO CONTRA LAS DECISIONES POR LAS QUE SE DENIEGA UNA SOLICITUD DE PROTECCIÓN INTERNACIONAL. VI. VALORACIÓN DE ESTA JURISPRUDENCIA DESDE LA PERSPECTIVA DE LA EFECTIVA APLICACIÓN DE LAS NORMAS DEL SECA. VII. CONSIDERACIONES FINALES. BIBLIOGRAFIA.

\section{INTRODUCCIÓN}

Las discrepancias en el seno del Consejo sobre buena parte de las propuestas presentadas por la Comisión Europea en 2016 para llevar a cabo una reforma en profundidad del $\mathrm{SECA}^{2}$, hasta la fecha han impedido la adopción de todo el paquete legislativo defendido por esta última institución de la Unión Europea (UE). Así lo admite con toda claridad la propia Comisión Europea ${ }^{3}$, para

2 A saber: la refundición del Reglamento de Dublín (COM2016 270 final); la refundición del Reglamento Eurodac (COM2016 194 final); el Reglamento por el que se establece la Agencia de Asilo de la UE (COM2016 271 final); el Reglamento sobre los procedimientos de asilo (COM2016 467 final); el Reglamento sobre requisitos para la protección internacional (COM2016 466 final); la refundición de la Directiva sobre las condiciones de acogida (COM2016 465 final); y el Reglamento sobre el Marco de Reasentamiento de la Unión (COM2016 468 final). Además, en septiembre de 2018 la Comisión presentó la propuesta modificada de Reglamento relativo a la Agencia de Asilo de la UE (COM2018 633 final). Para un análisis de estas propuestas, véase Martínez Alarcón (2018: 231 y ss.).

3 "Aunque se realizaron avances significativos en algunas de estas propuestas, y los colegisladores llegaron a acuerdos políticos provisionales con respecto a las propuestas del Reglamento sobre requisitos para la protección internacional, la Directiva sobre las condiciones de acogida, el Reglamento Eurodac y la primera propuesta por la que se establece la Agencia de Asilo de la Unión Europea, se lograron menos avances en las propuestas para el Reglamento de Dublín y el Reglamento sobre los procedimien- 
justificar su nueva batería de reformas legislativas relativas al SECA, tras hacer público el denominado Nuevo Pacto sobre Migración y Asilo, en el que con carácter general se reconocen, con un tono diplomático, las deficiencias que presenta la aplicación del SECÁ

La sentencia dictada por la Gran Sala del TJ en el asunto C-808/18, Comisión/ Hungría (acogida de solicitantes de protección internacional) ${ }^{5}$-en adelante, Comisión/Hungría - confirma de forma muy contundente el diagnóstico que sobre las evidentes dificultades que durante los últimos años afectan a la correcta aplicación de las normas en vigor del DUE que regulan el SECA realizaba hace unos pocos meses la Comisión Europea. Los hechos juzgados en este asunto y la valoración jurídica que sobre los mismos lleva a cabo la instancia jurisdiccional de Luxemburgo, también ponen de manifiesto que muy probablemente la adopción de buena parte de las nuevas propuestas legislativas presentadas recientemente por la Comisión Europea se va a enfrentar a obstáculos cuya superación resulta ahora mismo muy incierta ${ }^{6}$. Y ello a la vista de las diferentes posturas políticas que mantienen las autoridades nacionales de los veintisiete Estados miembros representadas en el Consejo, en general, sobre cómo gestionar la presión migratoria que algunos de estos Estados viene soportando y, algo más en particular, sobre el

tos de asilo, principalmente debido a las discrepancias en el Consejo. Ni siquiera fue posible recabar apoyo suficiente para llegar a un acuerdo sobre algunas de las propuestas relacionadas con la reforma del sistema de asilo de cara a acordar la reforma completa»: COM (2020) 610 final, p. 3.

4 «Las incoherencias entre los sistemas nacionales de asilo y retorno, así como las deficiencias en su aplicación, han puesto de manifiesto ineficiencias y han suscitado preocupación por la equidad»: COM (2020) 609 final, p. 3.

5 Sentencia de 17 de diciembre de 2020, Comisión/Hungría, C-808/18, EU:C:2020:1029.

6 A saber: la propuesta de Reglamento sobre la gestión del asilo y la migración y por el que se modifica la Directiva 2003/109/CE del Consejo y la propuesta de Reglamento sobre el Fondo de Asilo y Migración (COM2020 610 final); la propuesta modificada de Reglamento por el que se establece un procedimiento común en materia de protección internacional en la Unión y se deroga la Directiva 2013/32 (COM2020 611 final); la propuesta de Reglamento por el que se introduce un control de nacionales de terceros países en las fronteras exteriores y se modifican los reglamentos 767/2008, 2017/2226, 2018/1240 y 2019/817 (COM2020 612 final); la propuesta de Reglamento relativo a las situaciones de crisis y de fuerza mayor en el ámbito de la migración y el asilo (COM2020 613 final); y la propuesta modificada de Reglamento relativo a la creación del sistema Eurodac (COM2020 614 final). 
cumplimiento de las normas internacionales y europeas que les obligan a conceder protección internacional a las personas que lleguen a su territorio ${ }^{7}$.

En efecto, durante la última década las autoridades húngaras, lideradas por su primer ministro Viktor Orbán, político conservador, nacionalista y con propuestas claramente xenófobas —en particular con relación a los inmigrantes de religión musulmana-, defensor de lo que se ha denominado un régimen político iliberal o antiliberal, vienen adoptando normativa interna que contraviene los valores propios de un Estado de derecho, lo que ha tenido como consecuencia que se presenten varios recursos por incumplimiento por parte de la Comisión Europea ${ }^{8}$. En Comisión/Hungría, el TJ llega a la

7 Desacuerdo que se hizo muy evidente con motivo del debate y aprobación por la Asamblea General de Naciones Unidas, por una amplia mayoría de 152 votos a favor, 5 en contra y 12 abstenciones, de un texto jurídicamente no vinculante, del Pacto Mundial para la Migración Segura, Ordenada y Regular (Resolución 73/195 de 19 de diciembre de 2018): tres Estados miembros de la UE (Hungría, Polonia y República Checa) votaron en contra - junto con Estados Unidos e Israel-; otros cinco se abstuvieron (Austria, Bulgaria, Italia, Letonia y Rumanía); y Eslovaquia no participó en la votación: https://undocs.org/es/A/73/PV.60. Además, el voto a favor de Bélgica provocaría la dimisión de su primer ministro y la ruptura del Gobierno de coalición. (Todas las direcciones de internet que se citan en este trabajo, han sido consultadas por el última vez el 30 de enero de 2021).

8 Recursos que han dado lugar a la Sentencia de 18 de junio de 2020, Comisión/Hungría (Transparencia Asociativa), C-78/18, EU:C:2020:476, en la que se declara que la normativa húngara que obliga a las organizaciones no gubernamentales que reciben donaciones procedentes del extranjero a registrarse como tales ante los órganos jurisdiccionales húngaros y a hacer públicos el nombre del donante y el importe recibido, exponiéndose a ser sancionadas en caso de no respetar esta obligación, incumple el art. 63 del TFUE (libre circulación de capitales) y los arts. 7 (respeto de la vida privada y familiar), 8 (protección de datos de carácter personal) y 12 (libertad de asociación) de la CDFUE. Y a la Sentencia de 6 de octubre de 2020, Comisión/Hungría (Enseñanza Superior), C-66/18, EU:C:2020:792, en la que se declara que la normativa húngara que preceptúa que una institución de enseñanza superior extranjera solo podrá ejercer en el territorio de Hungría una actividad docente sancionada con un título si el Gobierno húngaro y el Gobierno del Estado en que tenga su sede la institución de enseñanza superior extranjera han manifestado su consentimiento en obligarse por un tratado internacional celebrado entre ambas partes relativo al apoyo de principio concedido a la institución para ejercer una actividad en Hungría, vulnera el art. XVII del Acuerdo General sobre el Comercio de Servicios, y los arts. 13 (libertad de cátedra), 14.3 (libertad de creación de centros docentes) y 16 (libertad de empresa) de la CDFUE. Como se ha dicho, esta jurisprudencia confirma un patrón de conducta seguido por el Gobierno de Orbán, consistente en la utilización partidista del poder legislativo para 
conclusión de que la práctica legislativa y administrativa húngara constituye una flagrante vulneración de tres directivas adoptadas de conformidad con la competencia compartida relativa a la política común de asilo - directivas 2013/32/UE (Directiva de procedimientos) y 2013/33/UE (Directiva de condiciones de acogida) —, y a la política común de inmigración —Directiva 2008/115/CE (Directiva de retorno)—, previstas en los arts. 78 y 79 TFUE, respectivamente. Con esta normativa la UE pretende asegurar, en alguna medida, una aplicación uniforme por sus ventisiete Estados miembros de la Convención sobre el Estatuto de los Refugiados de 28 de julio de 1951, y de su Protocolo de 31 de enero de $1967^{\circ}$. Como se prevé en el art. 18 de la Carta de los Derechos Fundamentales (CDFUE), en el que se regula el derecho de asilo mediante una remisión a este tratado internacional, y, por supuesto, de conformidad con el TUE y el TFUE.

Se trata de un incumplimiento del DUE que se prolonga al menos desde septiembre de 2015 y hasta septiembre de 2019. Durante este período las autoridades húngaras consideraron que la situación de crisis provocada por una inmigración masiva ${ }^{10}$ constituía una situación especial que en su opinión justificaba la aplicación de "procedimientos específicos», con los que se dejaba de lado el cumplimiento de las obligaciones internacionales asumidas por Hungría ${ }^{11}$, y

adoptar normas jurídicas dirigidas a eliminar cualquier oposición política al régimen: Sosa Navarro (2020: 17).

9 Ambos textos convencionales publicados en BOE 252, de 21 de octubre de 1978. Sobre la interpretación del art. 18 de la CDFUE, de conformidad con la Convención de 1951, para valorar la validez de las normas de derecho derivado, y en particular en este asunto el art. 14, apdos. 4, 5 (en los que se prevén los supuestos en los que los Estados miembros pueden revocar o denegar la concesión del estatuto de refugiado) y 6 (en el que se prevé que, no obstante, de aplicarse los anteriores apartados tales personas disfrutan de una serie de derechos contemplados en la Convención de Ginebra), de la Directiva 2011/95 que será citada a continuación, véase, entre otras, la Sentencia M, C-391/16, C-77/17 y C-78/17, EU:C:2019:403.

10 En concreto, en 2015 llegaron a territorio húngaro unos 400000 nacionales de terceros países; en los siguientes años esta cifra disminuyó considerablemente (a 19221 en 2016...), a pesar de que el Gobierno magiar siguió considerando que se mantenía una situación de crisis migratoria que justificaba medidas excepcionales: Armstrong (2019: 58-60).

11 Véase el informe de la Comisaria de Derechos Humanos del Consejo de Europa, en el que se concluye que «Commissioner finds that the stance against immigration and asylum seekers adopted by the government since 2015 has resulted in a legislative framework which undermines the reception of asylum seekers and the integration of recognised refugees as prescribed by international human rights obligations. Under 
también de la normativa de la UE sobre protección internacional que vincula a este mismo Estado ${ }^{12}$. Pero como se va a comprobar en los siguientes epígrafes, ni la Comisión Europea en la fase administrativa del procedimiento por incumplimiento $^{13}$, ni después el TJ en su sentencia en este asunto, van a aceptar las alegaciones presentadas por las autoridades húngaras.

En las páginas que siguen se va a dedicar un epígrafe al análisis de cada uno de los cuatro motivos de incumplimiento del DUE que son declarados por el TJ en Comisión/Hungría. Se ha considerado que, dada la gravedad y persistencia del incumplimiento de la normativa del SECA protagonizado por las autoridades húngaras, está justificado que respecto de cada uno de los motivos se dé cuenta de la postura jurídica mantenida por las partes en este asunto y del desarrollo de la argumentación jurídica que lleva a cabo el TJ para fundamentar su sentencia. Todo ello en el complejo contexto que se presenta en la actualidad para la aplicación de las normas en vigor que conforman el SECA $^{14}$. Como así lo demuestra la jurisprudencia del TJ en este sector de

the "crisis situation due to mass immigration", decreed by the government in September 2015 and still in force despite a greatly diminished number of asylum seekers, special legislation applies in the treatment of asylum seekers in violation of European and international asylum law»: Commissioner for Human Rights of the Council of Europe (2019: 4, y 7 y ss).

12 Conclusiones del abogado general Pikamäe, Comisión/Hungría, C-808/18, EU:C: 2020:493, de 25 de junio de 2020, punto 45 y nota a pie 10 que lo acompaña (en adelante, Conclusiones).

13 El 11 de diciembre de 2015, la Comisión envió un escrito de requerimiento a Hungría en el que se denunciaba la infracción del DUE por parte de este Estado, seguido de un escrito de requerimiento complementario el 18 de mayo de 2017, y de un dictamen motivado el 8 de diciembre de 2017, interponiendo el recurso por incumplimiento ante el TJ el 21 de diciembre de 2018.

14 Fundamentalmente las denominadas directivas de reconocimiento, de procedimientos y de condiciones de acogida, y los reglamentos de Dublín y Eurodac. A las que se debe añadir, por la evidente interrelación que presenta, la Directiva de retorno, en el ámbito de la política común de inmigración (art. 79 TFUE), porque como es obvio los nacionales de terceros Estados o apátridas a los que no se les reconoce la protección internacional podrán ser expulsados a un tercer Estado, de conformidad con las condiciones y el procedimiento establecidos en esta directiva. Véanse: Directiva 2011/95/UE del Parlamento Europeo y del Consejo, de 13 de diciembre de 2011, por la que se establecen normas relativas a los requisitos para el reconocimiento de nacionales de terceros países o apátridas como beneficiarios de protección internacional, a un estatuto uniforme para los refugiados o para las personas con derecho a protección subsidiaria y al contenido de la protección concedida (DO L 337, de 20 de diciembre de 2011); Directiva 2013/32/UE del Parlamento Europeo y del Consejo, de 26 de 
normas, sobre todo en el ámbito de su respuesta a cuestiones prejudiciales ${ }^{15} \mathrm{y}$ más en concreto con relación a Hungría ${ }^{16}$; y también, aunque hasta ahora en

junio de 2013, sobre procedimientos comunes para la concesión o la retirada de la protección internacional (DO L 180, de 29 de junio de 2013); Directiva 2013/33/UE del Parlamento Europeo y del Consejo, de 26 de junio de 2013, por la que se aprueban normas para la acogida de los solicitantes de protección internacional (DO L 180, de 29 de junio de 2013); Reglamento 604/2013 del Parlamento Europeo y del Consejo, de 26 de junio de 2013, por el que se establecen los criterios y mecanismos de determinación del Estado miembro responsable del examen de una solicitud de protección internacional presentada en uno de los Estados miembros por un nacional de un tercer país o un apátrida (DO L 180, de 29 de junio de 2013); Reglamento 603/2013 del Parlamento Europeo y del Consejo, de 26 de junio de 2013, relativo a la creación del sistema "Eurodac» para la comparación de las impresiones dactilares para la aplicación efectiva del Reglamento 604/2013 (DO L 180, de 29 de junio de 2013). También se deben citar el Reglamento 439/2010 del Parlamento Europeo y del Consejo, de 19 de mayo de 2010, por el que se crea una Oficina Europea de Apoyo al Asilo (DO L 132, de 29 de mayo de 2010); y el Reglamento 516/2014 del Parlamento Europeo y del Consejo, de 16 de abril de 2014, por el que se crea el Fondo de Asilo, Migración e Integración (DO L 150, de 20 de mayo de 2014). A los que se debe añadir la hasta la fecha nunca aplicada Directiva 2001/55/CE del Consejo, de 20 de julio de 2001, relativa a las normas mínimas para la concesión de protección temporal en caso de afluencia masiva de personas desplazadas (DO L 212, de 7 de agosto de 2001). Como se ha señalado, asimismo se debe tener en cuenta la Directiva 2008/115/CE del Parlamento Europeo y del Consejo, de 16 de diciembre de 2008, relativa a normas y procedimientos comunes en los Estados miembros para el retorno de los nacionales de terceros países en situación irregular (DO L 348, de 24 de diciembre de 2008).

15 Sobre la jurisprudencia del TJ, véanse Martínez Alarcón (2019: 511 y ss.) y Ortega Terol (2018: 183-191).

16 Cabe destacar la Sentencia de 14 de mayo de 2020, FMS y otros, C-924/19 PPV y C-925/19 PPV, EV:C:2020:367, un asunto en el que se plantea la conformidad con el DUE del procedimiento seguido por las autoridades húngaras para denegar la solicitud de protección internacional y la posterior expulsión a Afganistán e Irán de solicitantes de protección internacional nacionales de estos dos Estados —uno de ellos menor de edad- que se encuentran internados durante varios meses en la zona de tránsito de Röske, tras no haberse podido ejecutar la orden previa de expulsión a Serbia ante el rechazo de las autoridades de este Estado a admitirlos en su territorio. El TJ se pronuncia sobre varias incompatibilidades que presenta la normativa interna de Hungría con la normativa de la UE sobre protección internacional. Después de aplicar el procedimiento prejudicial por urgencia teniendo en cuenta la situación en la que se encuentran los demandantes en el litigio principal (lo que permitirá dictar sentencia en menos de cinco meses desde que se presentó la cuestión prejudicial el 
muy pocos casos, a recursos por incumplimiento, a los que se hará referencia más adelante. A continuación, se incluye un epígrafe con el que se valora esta jurisprudencia desde la perspectiva de la efectiva aplicación de las normas del SECA. Y se añade un apartado de consideraciones finales, con el que se ofrecen algunas reflexiones generales a modo de conclusión.

\section{HUNGRÍA IMPIDE EL ACCESO AL PROCEDIMIENTO DE PROTECCIÓN INTERNACIONAL}

La Comisión sostiene que Hungría incumple los arts. 3 y 6 de la Directiva 2013/32 (Directiva de procedimientos) ${ }^{17}$. En efecto, según la normativa húngara en vigor en el marco de la situación especial declarada como respuesta a la crisis migratoria, durante el período comprendido entre

18 de diciembre de 2019), hace uso de forma ejemplar de los principios de primacía y eficacia directa del DUE y del principio de cooperación leal (art. 4.3 TUE), así como del derecho a la tutela judicial efectiva previsto en el art. 47 de la CDFUE, siempre con el objetivo de garantizar la efectiva aplicación del DUE. Unos meses más tarde, algunas de tales incompatibilidades serán confirmadas por el TJ como incumplimientos del DUE en su sentencia en el asunto C-808/18, como se comprobará en las siguientes páginas. También se pueden citar otras sentencias del TJ dictadas como respuesta a cuestiones prejudiciales presentadas por órganos judiciales húngaros relativas a la interpretación de la normativa del SECA: sentencias de 17 de marzo de 2016, Shiraz Baig Mirza, C-695/15 PPU, EU:C:2016:188; de 13 de septiembre de 2018, Shajin Ahmed, C-369/17, EU:C:2018:713; de 29 de julio de 2019, Alekszij Torubarov, C-556/17, EU:C:2019:626; de 19 de marzo de 2020, PG, C-406/18, EU:C:2020:216; y de 19 de marzo de 2020, LH, C-564/18, EU:C: 2020:218.

17 Según el art. 3.1, «la presente Directiva se aplicará a todas las solicitudes de protección internacional presentadas en el territorio, con inclusión de la frontera, en las aguas territoriales o en las zonas de tránsito de los Estados miembros, y a la retirada de la protección internacional». Según el art. 6.1, «cuando una persona formule una solicitud de protección internacional a una autoridad competente para el registro de estas solicitudes con arreglo al Derecho nacional, el registro se realizará en el plazo máximo de los tres días hábiles siguientes a que se formule la solicitud»; y si se presenta ante otras autoridades que no sean competentes, el registro deberá realizarse en el plazo de 6 días; además, en caso de una solicitud simultánea por parte de gran número de solicitantes que haga muy difícil en la práctica cumplir este plazo, se podrá ampliar hasta los diez días hábiles. El art. 6.2 preceptúa que «los Estados miembros garantizarán que la persona que haya formulado una solicitud de protección internacional tenga efectivamente la oportunidad de presentarla lo antes posible». 
septiembre de 2015 y septiembre de 2019 las solicitudes de protección internacional deben presentarse en persona y exclusivamente en las dos zonas de tránsito en la frontera entre Serbia y Hungría, en Röszke y Tompa. Las autoridades húngaras solo autorizan un número muy limitado de entradas en esas zonas — durante algunos períodos, solamente dos personas al día—, lo que supone que los solicitantes de protección internacional deben esperar más de once meses, en una estrecha franja de terreno carente de toda infraestructura que linda con territorios serbios, para poder acceder a una de las dos zonas de tránsito. El TJ acepta como probados estos hechos, de conformidad con los informes del ACNUR que aporta la Comisión Europea; informes que gozan de una "pertinencia especial», teniendo en cuenta el papel que corresponde al ACNUR según la Convención de 1951, tratado internacional que debe ser «observado» a la hora de interpretar las normas del DUE sobre asilo ${ }^{18}$. Por tanto, para el TJ ha quedado demostrado que las autoridades húngaras han impedido de forma "sistemática» y «drástica» el acceso a las zonas de tránsito de Röske y de Tompa, consiguiendo que sea casi imposible formular una solicitud de protección internacional en Hungría ${ }^{19}$.

Según mantiene el TJ, reiterando su jurisprudencia anterior en Ministerio Fiscal ${ }^{20}$, la aplicación de la Directiva 2013/32 obliga a los Estados a que

18 Apdo. 115. Se cita a este respecto la Sentencia de 23 de mayo de 2019, Bilali, C-720/17, EU:C:2019:448, apdo. 57.

19 Apdo. 118.

20 Sentencia de 25 de junio de 2020, Ministerio Fiscal, C-36/20, EU:C:2020:495, apdos. 82 y 92-94. La respuesta del TJ a esta cuestión prejudicial está referida a la interpretación y aplicación de la normativa de la UE sobre protección internacional a un nacional de Mali, VL. Después de llegar en patera a Gran Canaria, las autoridades administrativas españolas ordenan su devolución y al no poder ejecutarse la misma en el plazo de 72 horas previsto en la normativa, instan su ingreso en un centro de internamiento ante el juzgado de instrucción competente. En su comparecencia ante el juzgado de instrucción, VL manifiesta su intención de solicitar protección internacional y alega que, si lo expulsan a Mali, país que está en guerra, lo expondrían al riesgo de que lo maten. Al no ser el juzgado de instrucción el órgano competente según el derecho español para decidir sobre la solicitud de protección internacional, traslada la declaración de VL a las autoridades administrativas competentes y decide su ingreso en un centro de internamiento de extranjeros, dado que no le encontraron plaza en ningún centro de acogida humanitaria. En aplicación del procedimiento prejudicial de urgencia (puesto que VL estaba privado de libertad y sobre él pesaba una orden de devolución que podía ejecutarse en cualquier momento), el TJ llega a la conclusión de que el juez de instrucción ante el que se insta el internamiento de un nacional de un tercer país que se halla en situación irregular a los efectos de su 
garanticen al particular un acceso efectivo, sencillo y rápido al procedimiento de protección internacional $^{21}$. Si un Estado demora injustificadamente el momento en que se permite a la persona interesada que pueda formular la solicitud de protección internacional, se está menoscabando el efecto útil del art. 6 de la Directiva 2013/3222; y en definitiva, la efectividad del derecho de asilo regulado en el art. 18 de la CDFUE ${ }^{23}$. Por tanto, el art. 6 de la Directiva 2013/32 obliga a que los Estados miembros garanticen «que las personas interesadas puedan ejercer de manera efectiva el derecho a formular una solicitud de protección internacional, incluso en sus fronteras, tan pronto como manifiesten esa voluntad, con la finalidad de que la solicitud se registre y pueda presentarse y examinarse respetándose efectivamente los plazos establecidos por la citada Directiva ${ }^{24}$.

Al limitar de forma extremadamente severa el acceso a las mencionadas zonas de tránsito, las autoridades húngaras no conceden a las personas que se encuentran en su territorio la posibilidad de presentar una solicitud de protección internacional ${ }^{25}$. En definitiva, Hungría incumple el art. 6 de la Directiva 2013/32, en relación con su art. 3, ya que las autoridades húngaras únicamente permiten que las solicitudes de protección internacional se puedan formular en las zonas de tránsito de Röszke y de Tompa, al mismo tiempo que limitan drásticamente el número diario de solicitantes a los que se autoriza a entrar en las mismas ${ }^{26}$.

devolución está incluido entre las «otras autoridades» previstas en el art. 6.1 de la Directiva 2013/32 que pueden recibir solicitudes de protección internacional, a pesar de que no es competente para registrar tales solicitudes, y por tanto, debe informar a los nacionales de terceros países de las condiciones de presentación de las solicitudes de protección internacional y dar traslado a la autoridad competente de tales solicitudes para su registro; siempre teniendo en cuenta el objetivo que persigue el art. 6.1 de la Directiva 2013/32: "garantizar un acceso efectivo, sencillo y rápido al procedimiento de protección internacional»: apdo. 82 .

21 Apdo. 104.

22 Apdo. 103.

23 Apdo. 102.

24 Apdo. 106.

25 Entre otras cuestiones, el TJ pone de manifiesto que «es incontrovertido que no existe ninguna infraestructura en la franja de terreno que va desde la frontera serbo-húngara hasta la entrada de las zonas de tránsito de Röszke y de Tompa, de manera que resulta extremadamente difícil permanecer en dicha franja por un período prolongado»: apdo. 125 .

26 Apdo. 128. 


\section{HUNGRÍA INCUMPLE LAS NORMAS SOBRE EL INTERNAMIENTO DE LOS SOLICITANTES DE PROTECCIÓN INTERNACIONAL}

El TJ se pronuncia conjuntamente sobre las imputaciones segunda y tercera que presenta la Comisión Europea, relativas, respectivamente, a la infracción por las autoridades húngaras de los arts. 24, apdo. 3, y 43 de la Directiva 2013/32 (Directiva de procedimientos), y de los arts. 2, letra h), 8, 9 y 11 de la Directiva 2013/33 (Directiva de condiciones de acogida). Tales incumplimientos se cometen al internar de forma generalizada a los solicitantes de protección internacional en las zonas de tránsito de Röszke y de Tompa, sin que se respeten los procedimientos y garantías previstos en las citadas disposiciones ${ }^{27}$.

En efecto, las autoridades húngaras internan a todos los solicitantes de asilo, excepto los niños menores de catorce años no acompañados, durante todo el procedimiento de asilo, en las instalaciones de una de las dos zonas de tránsito. Alegan que no se trata de un internamiento, ya que los solicitantes pueden abandonarlas libremente, aunque solo en dirección a Serbia. Y citan a este respecto la sentencia del Tribunal Europeo de Derechos Humanos (TEDH) en Ilias and Ahmed v. Hungary, en la que la Gran Sala llega a la conclusión de que el internamiento en las zonas de tránsito no constituye una vulneración del art. 5.1 y 4 del CEDH, corrigiendo lo decidido en la sentencia de la Sala en este mismo asunto ${ }^{28}$. Muy en resumen y según la Gran Sala, los solicitantes han entrado por su propia voluntad en las zonas de tránsito, y no están privados de su libertad, puesto que pueden dirigirse libremente a Serbia, y por tanto no es de aplicación el art. 5 del $\mathrm{CEDH}^{29}$.

El TJ prescinde de toda referencia a la jurisprudencia del TEDH, y se muestra contundente a la hora de defender que en el marco del DUE se debe aplicar la noción de internamiento prevista en el art. 2.h) de la Directiva 2013/33, según el cual se define internamiento como «el confinamiento de

\section{Apdo. 155.}

28 Sentencia del TEDH de 14 de marzo de 2017, Ilias y Ahmed c. Hungría, ECHR:2017:0314JUD004728715.

29 Sentencia del TEDH (Gran Sala), de 21 de noviembre de 2019, CE:ECHR:2019:1121JUD004728715, párrs. 222 y 248. Conviene añadir que la Gran Sala confirma que Hungría vulnera el art. 3 del CEDH al expulsar a los solicitantes de protección internacional a Serbia sin examinar en cada caso si su expulsión a este último Estado puede dar lugar a que sufran torturas o tratos inhumanos, crueles o degradantes; conclusión a la que había llegado la Sala en su Sentencia de 2017: párr. 163. Para una crítica de la decisión de la Gran Sala de no considerar aplicable el art. 5 del CEDH, véase Ruiz Ramos (2020: 35-38). 
un solicitante por un Estado miembro en un lugar determinado donde se priva al solicitante de la libertad de circulación». A juicio del TJ, cabe aplicar un concepto autónomo de privación de libertad, propio del DUE de conformidad con el art. 6 CDFUE, según mantuvo en FMS y otros $^{30}$. Por lo que el internamiento de un solicitante de protección internacional «es un concepto autónomo del Derecho de la Unión, que se define como toda medida coercitiva que lo priva de la libertad de circulación y lo aísla del resto de la población, obligándolo a permanecer sin solución de continuidad en un perímetro restringido y cerrado ${ }^{31}$.

Los solicitantes de protección internacional internados en las zonas de tránsito de Hungría no tienen una posibilidad real de abandonarlas para dirigirse a Serbia, ya que, por una parte, su entrada en el territorio serbio sería considerada ilegal y se expondrían a sanciones. Además, por otra parte, si abandonan el territorio húngaro ya no podrán solicitar el estatuto de refugiado en Hungría, puesto que la normativa interna húngara prevé que si el solicitante abandona cualquiera de las dos zonas de tránsito se podrá archivar su expediente, sin que esa decisión pueda ser objeto de recurso ${ }^{32}$.

Una vez resuelta la aplicación del concepto de internamiento, en primer lugar el internamiento de solicitantes de protección internacional que llevan a cabo las autoridades húngaras incumple las condiciones y garantías previstas en el art. 43 de la Directiva 2013/32 33 , sin que se pueda justificar con ninguno

30 Apdo. 231 de esta sentencia en FM y otros.

31 Apdo. 159. El TJ añade que «los solicitantes de protección internacional que tienen como lugar de estancia la zona de tránsito de Röszke o la de Tompa están obligados a permanecer sin solución de continuidad en tales zonas, que están rodeadas de una valla de alambre de espino. Estos solicitantes se alojan en contenedores de una superficie que no supera los $13 \mathrm{~m}^{2}$. No pueden entrar en contacto con personas de fuera de la zona de tránsito en la que se encuentran, con excepción de su representante legal, y sus movimientos dentro de la misma están limitados y vigilados por los miembros de las fuerzas del orden presentes en todo momento dentro de ella y en sus inmediaciones»: apdo. 160.

32 Apdos. 164 y 165.

33 En el que se regulan los denominados «procedimientos fronterizos», aplicables en la frontera o en las zonas de tránsito. Según esta disposición, en el marco de tales procedimientos fronterizos los Estados miembros solo pueden tomar decisiones sobre el fondo de una solicitud en un procedimiento de conformidad con el art. 31.8; y se exige que la duración del procedimiento sea razonable y en todo caso no supere las cuatro semanas, pasadas las cuales se deberá conceder al solicitante la entrada al territorio del Estado para que se tramite su solicitud mediante los procedimientos previstos en la directiva. El art. 31.8 permite que los Estados miembros apliquen un 
de los motivos de internamiento que se prevén en el art. 8.3 de la Directiva $2013 / 33^{34}$. En efecto, el internamiento que llevan a cabo las autoridades húngaras no se corresponde con ninguno de los seis supuestos regulados en el art. 8.3, ya que tal internamiento se aplica de forma sistemática en las dos mencionadas zonas de tránsito, sin que se justifique si resulta necesario y si no se pueden aplicar efectivamente medidas menos coercitivas, y sin llevar a cabo una evaluación individual de la situación de cada solicitante de protección

procedimiento en la frontera o en zonas de tránsito, en un total de diez supuestos, entre los que destacan los siguientes: b) el solicitante procede de un país de origen seguro a efectos de la presente Directiva; c) el solicitante hubiese engañado a las autoridades mediante la presentación de información o documentación falsa [...] e) el solicitante hubiese formulado alegaciones claramente incoherentes y contradictorias, manifiestamente falsas u obviamente inverosímiles o que contradigan suficientemente información contrastada sobre el país de origen [...] y j) el solicitante pudiese ser considerado por razones graves un peligro para la seguridad nacional o el orden público del Estado miembro o hubiese sido expulsado con carácter ejecutorio por motivos graves de seguridad o de orden público con arreglo al derecho nacional.

El art. 8 prohíbe con carácter general el internamiento de una persona por la única razón de que sea un solicitante de protección internacional (como se reitera en el art. 26 de la Directiva 2013/32/UE). Si bien, el apdo. 3 de este art. 8 prevé hasta seis supuestos en los que cabe internar a un solicitante de protección internacional: a) para determinar o verificar su identidad o nacionalidad; b) para determinar los elementos en que se basa la solicitud, que no podrían obtenerse sin el internamiento, en particular cuando exista riesgo de fuga del solicitante; c) para decidir sobre el derecho del solicitante a entrar en el territorio, en el marco de un procedimiento; d) cuando la persona está sometida a un procedimiento de retorno en aplicación de la Directiva 2008/115, el Estado puede demostrar de conformidad con criterios objetivos que el interesado ya ha tenido la oportunidad de acceder al procedimiento de asilo, por lo que únicamente presenta la solicitud de protección internacional para retrasar o frustrar la ejecución de la decisión de retorno; e) cuando así lo exija la protección de la seguridad nacional y el orden público; f) de conformidad con lo dispuesto en el art. 28 del Reglamento $604 / 2013$, en el que se prevé el internamiento para poder hacer efectivo del traslado del interesado al Estado donde le corresponde presentar la solicitud de protección internacional. El TJ se ha pronunciado sobre la conformidad del art. 8.3 párr. primero letra e), con los arts. 6 y 52.1 y 3 de la CDFUE, en respuesta a cuestión prejudicial de validez en su Sentencia de 15 de febrero de 2016, J.N., C-601/15, EU:C:2016:84. Y sobre la conformidad del art. 8.3 párr. primero, apdos. a) y b), con los arts. 6 y 52.1 y 3 de la CDFUE, en respuesta a otra cuestión prejudicial de validez, en su Sentencia de 14 de septiembre de 2017, K, C-18/16, EU:C:2017:680. 
internacional, como en definitiva se exige para la aplicación de los apdos. 2 y 3 del art. 8 de la Directiva 2013/33 35 .

Más en concreto, por lo que se refiere a la posible aplicación del art. 8.3 párr. primero, letra c), que permite el internamiento de los solicitantes de protección internacional cuando los Estados miembros decidan aplicar los procedimientos fronterizos previstos en el art. 43 de la Directiva 2013/32, conviene destacar que Hungría hace uso de un procedimiento especial como norma general, según el cual todas las solicitudes de protección internacional deben tramitarse en las dos mencionadas zonas de tránsito. Pero la normativa interna húngara no limita el tiempo de internamiento al plazo máximo de cuatro semanas desde que se presenta la solicitud de protección internacional, tal y como se prevé en el citado art. $43^{36}$. Asimismo, la normativa húngara obliga a los solicitantes a permanecer en las zonas de tránsito durante todo el examen de su solicitud, y también durante el procedimiento judicial que en su caso se inicie si se impugna la decisión denegatoria de la solicitud. Esto contraviene el apdo. 1 del art. 43 de la Directiva 2013/32, en el que se establece que el internamiento solo se justifica a los efectos de permitir al Estado miembro que examine, antes de reconocer al solicitante de protección internacional el derecho a entrar en su territorio, si su solicitud no es inadmisible, en virtud del art. 33 de la Directiva 2013/32; o si no debe denegarse por infundada por alguno de los motivos enumerados en el art. 31, apdo. 8, de esta directiva. Por tanto, el internamiento que llevan a cabo las autoridades húngaras no puede justificarse con el citado art. 8.3, párr. primero, letra c) de la Directiva $2013 / 33^{37}$.

En segundo lugar, Hungría vulnera el art. 24.3 de la Directiva 2013/32, en el que se prevé que los Estados presten el «apoyo adecuado» a los solicitantes que necesiten garantías procedimentales especiales. Se debe entender por tales aquellos cuya capacidad de disfrutar los derechos y cumplir las obligaciones previstas en la citada directiva pueda estar limitada por circunstancias individuales, en cuyo caso no se les debe aplicar el art. $43^{38}$. En virtud del art. 11 de la misma directiva no se excluye absolutamente el internamiento de los solicitantes que necesiten garantías procedimentales especiales. Pero si son internados su estado de salud, incluido su estado de salud psíquica, debe

\footnotetext{
Apdos. 167-176.

Apdo. 182.

Apdo. 185.

38 En particular, se contempla el supuesto en el «que el solicitante necesita garantías procedimentales especiales por haber sido objeto de torturas, violación y otras formas graves de violencia psicológica, física o sexual»: art. 24.3, párr. segundo.
} 
ser una prioridad para los Estados miembros, que deben garantizar un control regular de estas personas y dispensarles un «apoyo adecuado» teniendo en cuenta su situación particular ${ }^{39}$.

Como ya se ha insistido, las autoridades húngaras aplican el mencionado procedimiento especial previsto en su normativa interna a todas las solicitudes de protección internacional, por lo que internan a todos los solicitantes de protección internacional en las zonas de tránsito de Röske y Tompa, con excepción de los menores de catorce años no acompañados. Además, no permiten que transcurridas las cuatro semanas desde que se presenta la solicitud, los solicitantes puedan salir de las zonas de tránsito. Deben permanecer en las mismas durante todo el procedimiento de examen de la solicitud de protección internacional $\mathrm{y}$, en su caso, durante todo el procedimiento judicial de examen del recurso con el que se impugne la decisión denegatoria de la solicitud. Y solo aplican las garantías procedimentales especiales que prevé el citado art. 24 de la Directiva 2013/32/UE a los menores no acompañados de menos de catorce años ${ }^{40}$. Por todo ello, Hungría no cumple con «la exigencia de tomar en consideración las necesidades específicas de estas categorías de solicitantes impuesta por el artículo 24.3, de la Directiva $2013 / 32 »^{41}$.

En tercer lugar, el internamiento se aplica durante todo el procedimiento de examen de su solicitud de protección internacional también a todos los menores, incluso los no acompañados mayores de catorce años. Ello contraviene el art. 11.2 de la citada Directiva 2013/33, en el que se prevé que únicamente se internará a los menores como medida de último recurso y tras haberse determinado la imposibilidad de aplicar eficazmente otras medidas menos coercitivas ${ }^{42}$.

En cuarto lugar, las autoridades húngaras llevan a cabo el internamiento de todos los solicitantes de protección internacional en las mencionadas zonas

Apdo. 190.

Apdos. 196 y 197.

Apdo. 198.

42 Apdo.203. Sobre la interpretación de los arts. 20.4 y 5 de la Directiva 2013/33 de conformidad con el art. 24 de la CDFUE y teniendo en cuenta especialmente el interés superior del menor, véase la Sentencia de 12 de noviembre de 2019, Zubair, C-233/18, EU:C:2019:956, en la que el TJ llega a la conclusión de que un Estado miembro no puede establecer como sanción a un solicitante de protección internacional en caso de violación grave de la normativa aplicable en los centros de acogida o de comportamiento violento grave, la sanción consistente en retirar las condiciones materiales de acogida relativas al alojamiento, a la alimentación o al vestido, ya que ello tendría como efecto privar al solicitante de satisfacer sus necesidades más elementales. 
de tránsito, sin que se dicte por escrito una orden de internamiento por una autoridad administrativa o judicial en la que se reflejen los motivos de hecho y de derecho en que se basa, como preceptúa el art. 9.2 de la misma Directiva $2013 / 33^{43}$.

Por último, el TJ rechaza que el art. 72 TFUE autorice a Hungría a declarar una situación de crisis provocada por una inmigración masiva y a aplicar respecto de esa situación unas normas de procedimiento de excepción con el fin de mantener el orden público y salvaguardar la seguridad interior. Normas con las que deja de cumplir la normativa de derecho derivado de la UE, en particular las citadas Directivas 2013/32 y 2013/33, y más en concreto los arts. 24.3 y 43 de la Directiva 2013/32. Debe tenerse en cuenta la interpretación que de esta disposición se lleva a cabo en Comisión/Polonia y otros, en el que se rechaza la aplicación del art. 72 para justificar el incumplimiento de las decisiones relativas al mecanismo temporal de reubicación de solicitantes de protección internacional ${ }^{44}$. Según el TJ,

43 Apdos. 206-208.

44 Sentencia de 2 de abril de 2020, Comisión/Polonia y otros, C-715/17, C-718/17 y C-719/17, EU:C:2020:257, apartados 139 a 172. En su respuesta a los recursos por incumplimiento presentados por la Comisión Europea, el TJ llega a la conclusión de que Polonia, República Checa y Hungría han incumplido la obligación prevista en el art. 5.2, al no haber comunicado, a intervalos regulares y, como mínimo, cada tres meses, un número adecuado de solicitantes de protección internacional que podín reubicar rápidamente en su territorio; y por consiguiente han incumplido las obligaciones en materia de reubicación previstas en el art. 5, apdos. 4 a 11, de las Decisiones (UE) 2015/1523, de 14 de septiembre de 2015, y 2015/1601, de 22 de septiembre de 2015, ambas del Consejo, relativas las dos al establecimiento de medidas provisionales en el ámbito de la protección internacional en favor de Italia y Grecia (DO L 239 y 248, de 15 y de 24 de septiembre de 2015, respectivamente) —en el caso de Hungría, al no serle de aplicación la Decisión 2015/1523, el incumplimiento es declarado con relación a la Decisión 2015/1601- El TJ se muestra contundente, al señalar que «de ello se sigue que el dispositivo previsto, en el marco del procedimiento de reubicación, en el artículo 5, apartados 4 y 7, de las Decisiones 2015/1523 y 2015/1601 solamente autorizaba a las autoridades competentes del Estado miembro de reubicación a invocar motivos fundados o razonables relativos al mantenimiento de la seguridad nacional o del orden público en su territorio tras haber examinado caso por caso el peligro actual o potencial que el solicitante de protección internacional en cuestión constituía para esos intereses. Se oponía por tanto [...] a que, en el marco de este procedimiento, un Estado miembro invocara perentoriamente el artículo 72 TFUE, a los solos fines de prevención general y sin demostrar la relación directa con un caso individual, para justificar la suspensión, o incluso el cese, del cumplimiento de las obligaciones que le incumbían en virtud de la Decisión 2015/1523 y/o de la Decisión 
[...] el Tratado FUE solo establece excepciones expresas aplicables en caso de situaciones que pueden poner en peligro el orden público o la seguridad pública en sus artículos $36,45,52,65,72,346$ y 347, que se refieren a unos supuestos excepcionales claramente delimitados. No puede deducirse de ello que exista una reserva general, inherente al Tratado FUE, que excluya del ámbito de aplicación del Derecho de la Unión cualquier medida adoptada por motivos de orden público o de seguridad pública. Reconocer la existencia de tal reserva al margen de las condiciones específicas previstas en las disposiciones de dicho Tratado podría contravenir el carácter imperativo y la aplicación uniforme del Derecho de la Unión ${ }^{45}$.

Además, el TJ deja bien claro que el art. 72 TFUE debe ser objeto de interpretación estricta, teniendo en cuenta la reiterada jurisprudencia en particular con relación a la aplicación de los arts. 346 y 347 TFUE. Por tanto, no cabe interpretar el art. 72 TFUE como si atribuyera a los Estados miembros la facultad de incumplir el DUE, «mediante la mera invocación de las responsabilidades que les incumben para el mantenimiento del orden público y la salvaguardia de la seguridad interior ${ }^{46}$.

A este respecto, el TJ insiste en que Hungría invoca de manera general los riesgos de alteración del orden público y la seguridad interior que puede causar una afluencia masiva de solicitantes de protección internacional, pero no demuestra la necesidad que tenía de no aplicar los arts. 24.3 y 43 de la Directiva 2013/32. Más en particular, no especifica el impacto que las infracciones cometidas en 2018 que el Gobierno húngaro asocia a la inmigración ilegal puedan tener en el mantenimiento del orden público y la salvaguardia de la seguridad interior en su territorio, ni por qué tales infracciones justifican el internamiento automático y masivo de los solicitantes de protección internacional sin cumplir las garantías previstas en dichos preceptos ${ }^{47}$.

Asimismo, el TJ pone de manifiesto que en varias disposiciones de las dos directivas 2013/32 y 2013/33 se prevén supuestos excepcionales en los que ya se permite a los Estados un importante margen de flexibilidad en su aplicación. En concreto, el art. 8.3 de la Directiva 2013/33 permite al Estado miembro internar a cualquier solicitante de protección internacional si así lo

2015/1601»: apdo. 160. Como es obvio, ese examen caso por caso solo se podía dar una vez el Estado comunicara el número de solicitantes que estaba dispuesto a reubicar y a su vez se le comunicarán al Estado la lista de solicitantes que podían ser objeto de esa reubicación, a los efectos de que pudiera llevarse a cabo un análisis individualizado de cada uno de ellos: apdo. 161.

45 Apdo. 214.

46 Apdo. 215.

47 Apdos. 217-220. 
exige la protección de la seguridad nacional y el orden público, siempre que se acredite que el comportamiento individual del solicitante representa una amenaza real, actual y suficientemente grave que afecta a un interés fundamental de la sociedad o de la seguridad interior o exterior del Estado miembro de que se trate ${ }^{48}$. Además, los arts. 10.1 y 18.9 de la Directiva 2013/33 permiten inaplicar parcialmente las disposiciones de esta directiva si se agotan las plazas en los centros de internamiento o en los centros de acogida ${ }^{49}$. Y en el art. 43.3 de la Directiva 2013/32 se permite que, en caso de afluencia masiva de solicitantes de protección internacional en las fronteras de un Estado miembro o en las zonas de tránsito de este, se tramiten los procedimientos fronterizos en un plazo superior a las cuatro semanas, limitando al mismo tiempo la libertad de circulación de los solicitantes a una zona situada en las proximidades de sus fronteras o de sus zonas de tránsito ${ }^{50}$.

En definitiva, Hungría no puede ampararse en el art. 72 TFUE para justificar el incumplimiento de las obligaciones previstas en los arts. 24, apdo. 3, y 43 de la Directiva 2013/32. Por lo que el TJ concluye que Hungría ha incumplido los arts. 24.3 y 43 de la Directiva 2013/32 —Directiva de procedimientos-, y los arts. 8, 9 y 11 de la Directiva 2013/33 — Directiva de condiciones de acogida-, al internar de forma generalizada a todos los solicitantes de protección internacional en las zonas de tránsito de Röske y de Tompa ${ }^{51}$.

\section{HUNGRÍA INCUMPLE LAS GARANTÍAS Y PROCEDIMIENTOS DE RETORNO}

Siempre en aplicación de su normativa interna, la policía húngara traslada coactivamente a la frontera a todos los nacionales de terceros países en situación irregular detenidos en el territorio de Hungría, y les obliga a cruzar la valla fronteriza, construida dentro del territorio de este Estado, a unos sesenta metros de la frontera exterior con Serbia. Se trata de una estrecha franja de

\footnotetext{
Apdo. 221.

Apdo. 223.

50 Apdo. 224. En FMS y otros, el TJ deja bien claro que «el artículo 43.3 de la Directiva 2013/32 no autoriza a un Estado miembro a internar a los solicitantes de protección internacional en sus fronteras o en una de las zonas de tránsito más allá del plazo de cuatro semanas..., aun cuando, debido a la llegada masiva de solicitantes de protección internacional, sea imposible aplicar los procedimientos mencionados en el artículo 43, apartado 1, de dicha Directiva en dicho plazo»: apdo. 246.

51 Apdos. 225 y 226.
} 
territorio fronterizo de Hungría, en la que no existe ninguna infraestructura y en la que no hay ningún medio para llegar al resto del territorio húngaro. En tales condiciones, los nacionales de terceros países no tienen otra opción que abandonar el territorio húngaro y dirigirse a Serbia. Aunque «técnicamente» la policía húngara no traslada a los nacionales de terceros Estados fuera del territorio de Hungría, la práctica descrita constituye, según la Comisión Europea, una expulsión. Expulsión que se lleva a cabo sin que se dicte una decisión de retorno, indiscriminadamente, sin tener en cuenta el interés superior del menor, la vida familiar, el estado de salud del nacional de un tercer país de que se trate y sin respetar el principio de no devolución. Además, los nacionales de terceros países no reciben ninguna justificación ni explicación por escrito de su expulsión, y no disponen de ninguna vía de recurso. Por lo que según la Comisión Europea se vulneran las garantías y procedimientos regulados en los arts. 5, 6.1, 12.1 y 13.1 de la Directiva 2008/115 (Directiva de retorno) ${ }^{52}$. Hungría alega que no es de aplicación la Directiva 2008/115, de conformidad con su art. 2.2.a). Pero la práctica descrita se aplica, según se establece expresamente en la normativa húngara, a todos los nacionales de terceros países que se encuentren en cualquier lugar del territorio de Hungría, y no solo a aquellos que hayan sido detenidos o interceptados en el momento del cruce irregular de la frontera exterior o tras ese cruce en las proximidades de esta $^{53}$, como se prevé en el art. 2.2.a) de la Directiva 2008/11 $15^{54}$.

Asimismo, Hungría alega que su Policía no expulsa a los nacionales de terceros países, ya que se limita a trasladarlos a determinados zonas cercanas a su frontera con Serbia, pero dentro del territorio húngaro, sin que se produzca un retorno efectivo a ningún tercer país, como así se exige en el art. 3.5 de la Directiva 2008/115. Pero el TJ sostiene que aunque este último precepto define la expulsión como el transporte físico de un nacional de un tercer Estado fuera del Estado miembro en ejecución de la obligación de retornar, «las garantías que acompañan a los procedimientos de retorno y de expulsión establecidas en esta Directiva quedarían privadas de su efecto útil si un Estado

52 Apdo. 227.

53 Según el TJ, la expresión «con ocasión del cruce irregular» implica «una relación temporal y espacial directa entre la detención o intercepción del nacional de un tercer país y el cruce de una frontera exterior», y que "se está aludiendo, pues, a nacionales de terceros países que han sido detenidos o interceptados por las autoridades competentes justo en el momento en que cruzaban de forma ilegal la frontera exterior o cuando, habiéndola ya cruzado, se hallaban en las proximidades de esta»: Sentencia de 19 de marzo de 2019, Arib y otros, C-444/17, EU:C:2019:220, apartado 46 (cursiva añadida).

54 Apdo. 246. 
miembro pudiera eximirse de la observancia de las mismas cuando efectúa un traslado coactivo de un nacional de un tercer país que equivale, en la práctica, a su transporte físico fuera de su territorio ${ }^{55}$.

Para el TJ, por una parte, los solicitantes de protección internacional son trasladados coactivamente a una estrecha franja de terreno desprovista de cualquier infraestructura; por tanto, no les queda otra opción que abandonar territorio húngaro y entrar en Serbia para poder alojarse y alimentarse. Por otra, los solicitantes de protección internacional que se encuentran en esa estrecha franja de terreno no disponen de la posibilidad efectiva de ingresar en una de las dos zonas de tránsito, de Röske o de Tompa, para poder formular una solicitud de protección internacional. Como ya se ha señalado, las autoridades húngaras restringen drásticamente el acceso a las zonas de tránsito, de modo que durante algunos períodos solo permiten entrar a dos personas al día ${ }^{56}$.

Tales incumplimientos tampoco pueden estar justificados por el art. 72 TFUE, en relación con el art. 4 TUE, como alega Hungría. Este Estado miembro se limita a invocar, de manera general, un riesgo de alteración del orden público y de la seguridad nacional «sin demostrar de modo suficiente en Derecho la necesidad que tenía de apartarse específicamente de lo dispuesto en la Directiva 2008/115 ${ }^{57}$. Más en concreto, Hungría no demuestra que la preservación efectiva de las funciones estatales esenciales a las que se refiere el art. 4.2 TUE, como la de proteger la seguridad nacional, solo pudiera garantizarse mediante la inaplicación de la Directiva 2008/115

Asimismo, el TJ también rechaza la invocación del art. 18 de la Directiva 2008/115. Esta disposición prevé situaciones de emergencia debidas a un número excepcionalmente importante de nacionales de terceros países que deben ser retornados, que planteen una importante carga imprevista para la capacidad de sus instalaciones de internamiento o para su personal administrativo o judicial; y permite que los Estados miembros dejen de cumplir algunas normas relativas al internamiento. Pero al mismo tiempo impone la obligación general de tomar todas las medidas adecuadas para garantizar el cumplimiento de las obligaciones que establece la Directiva 2008/115 .

\footnotetext{
Apdo. 256.

Apdos. 257-260.

7 Apartado 261, en el que cita, por analogía, la Sentencia de 2 de julio de 2020, Stadt Frankfurt am Main, C-18/19, EU:C:2020:511, apdos. 27 a 29.

58 Apdo. 262.

59 Apdo. 264. Sobre la interpretación del art. 18 de la Directiva 2008/115, véase la Sentencia de 2 de julio de 2020, WM, C-18/19, EU:C:2020:511.
} 
En definitiva, el TJ declara que Hungría incumple los arts. 5, 6.1, 12.1 y 13.1 de la Directiva 2008/115, al permitir la expulsión de todos los nacionales de terceros países en situación irregular que se encuentren en su territorio, a excepción de aquellos sospechosos de haber cometido una infracción, contraviniendo los procedimientos y garantías que se establecen en las citadas disposiciones $^{60}$.

\section{EN HUNGRÍA NO EXISTEN RECURSOS CON EFECTO SUSPENSIVO CONTRA LAS DECISIONES POR LAS QUE SE DENIEGA UNA SOLICITUD DE PROTECCIÓN INTERNACIONAL}

Según la Comisión, Hungría vulnera el art. 46.5 de la Directiva 2013/32 (Directiva de procedimientos), ya que en su normativa interna no se prevé un recurso con efecto suspensivo cuando se deniega una solicitud de protección internacional. Por tanto, no se garantiza el derecho de los solicitantes de asilo a permanecer en el territorio de Hungría a la espera del resultado del recurso; las decisiones de denegación son ejecutivas y se les puede expulsar inmediatamente ${ }^{61}$.

El TJ considera, en primer lugar, que por permanencia en el territorio debe entenderse la permanencia en el territorio del Estado en el que se ha formulado o se está examinando la solicitud de protección internacional, incluidas las fronteras o las zonas de tránsito ${ }^{62}$. En segundo lugar, según el art. 3.1 de la Directiva 2013/33, el solicitante de protección internacional ha de disfrutar de las condiciones de acogida contempladas en esta directiva mientras esté autorizado a permanecer en el territorio del Estado miembro; y según el art. 2.b), el nacional de un tercer país o apátrida debe ser considerado solicitante de protección internacional hasta que se resuelva definitivamente sobre su solicitud ${ }^{63}$.

Para el TJ, se debe aplicar el mismo concepto de resolución definitiva respecto de la aplicación de las disposiciones de las dos directivas, la 2013/32 y la 2013/33; a saber, «toda resolución por la cual se establece si se concede o no al interesado el estatuto de refugiado o de protección subsidiaria y contra la que ya no puede interponerse recurso en el marco de lo dispuesto en el capítulo $\mathrm{V}$ de dicha Directiva, con independencia de que el recurso tenga

\footnotetext{
Apdo. 266.

Apdos. 267-274.

Apdo. 283.

Apdo. 285.
} 
el efecto de permitir que el solicitante de protección internacional permanezca en el Estado miembro de que se trate a la espera de su resolución». Por tanto, un Estado miembro solamente pude fijar condiciones de este derecho a permanecer en el territorio del Estado miembro mientras se espera la resolución definitiva del recurso, en la medida que sean conformes con las directivas 2013/32 y 2013/33 $3^{64}$.

$\mathrm{Y}$ en tercer lugar, si un Estado miembro decide fijar condiciones para el ejercicio del derecho previsto en el art. 46.5 de la Directiva 2013/32, debe hacerlo con la suficiente claridad y precisión para que el solicitante de protección internacional pueda conocer el alcance exacto de tal derecho y para que se pueda apreciar si tales condiciones de ejercicio son conformes con las directivas 2013/32 y 2013/3365.

En este sentido, las condiciones de internamiento que la normativa interna húngara prevé para los solicitantes de asilo mientras esté pendiente de resolución el recurso contra la decisión por la que se haya denegado su solicitud, mediante un internamiento generalizado en las zonas de Röske y Tompa, vulneran los arts. 24.3 y 43 de la Directiva 2013/32, y los arts. 8, 9 y 11 de la Directiva 2013/33. Más en concreto, no se cumple ninguno de los supuestos previstos en el art. 8.3 de la Directiva 2013/33 para internar a un solicitante de protección internacional cuya solicitud haya sido denegada en primer grado por la autoridad decisoria y aún disponga de plazo para interponer un recurso contra esa decisión o lo haya interpuesto. Según el TJ, un Estado miembro no puede imponer a un solicitante de protección internacional condiciones de ejercicio al derecho a permanecer en su territorio previsto en el art. 46.5 de la Directiva 2013/32 que vulneren derechos garantizados a los solicitantes de protección internacional por las directivas 2013/32 y 2013/33. Hungría, al supeditar el ejercicio del derecho a permanecer en su territorio previsto en el art. 46.5 a la condición de que estén internados, en vulneración de las directivas 2013/32 y 2013/33, está vulnerando el art. $46.5^{66}$.

Asimismo, Hungría también incumple el art. 46.5 al supeditar el ejercicio del derecho a permanecer en su territorio a que el solicitante resida en un lugar determinado de su territorio. La normativa húngara solo prevé el internamiento en las dos zonas de tránsito, y no identifica con claridad y precisión las condiciones para el ejercicio del derecho previsto en el art. 46.5, para que

64 Apdos. 286 y 287.

65 Apdo. 289.

66 Apdos. 291-294. 
se pueda apreciar si tales condiciones que impone la normativa húngara son compatibles con las directivas 2013/32 y 2013/3367.

El TJ rechaza las otras dos imputaciones de la Comisión en este apartado, relativas, respectivamente, a la vulneración del art. 46.6 y del art. 46.6 letras a) y b) de la Directiva 2013/32. En ambos casos la Comisión reprocha a Hungría no haber traspuesto con suficiente claridad y precisión lo establecido en estas disposiciones. Pero el TJ considera que la normativa interna húngara transpone de forma correcta y completa lo preceptuado en estas normas. Respecto de la primera imputación, porque la normativa húngara permite instar ante un tribunal la suspensión de la decisión administrativa impugnada por la que no se concede protección internacional. Con relación a la segunda, porque la normativa húngara prevé, o al menos no impide, que los recursos presentados contra la decisión de denegación de protección internacional en los supuestos contemplados en el citado art. 46.6, letras a) y b), tengan efectos suspensivos automáticos ${ }^{68}$.

\section{VALORACIÓN DE ESTA JURISPRUDENCIA DESDE LA PERSPECTIVA DE LA EFECTIVA APLICACIÓN DE LAS NORMAS DEL SECA}

A la vista del breve análisis que se acaba de ofrecer en los anteriores epígrafes, pocos reproches, por no decir ninguno, se le pueden hacer a la argumentación jurídica que desarrolla el TJ en Comisión/Hungría. En este asunto llega a la conclusión de que durante los últimos años las autoridades húngaras han hecho caso omiso a las normas del DUE que les obligan a conceder protección internacional a los nacionales de terceros Estados y apátridas que lleguen a su territorio. Que el incumplimiento de tales normas protagonizado por las autoridades húngaras se pueda calificar de flagrante y persistente no es óbice para que se reconozca la correcta construcción jurídica que el TJ lleva a cabo de su sentencia en este asunto. Como se insistirá en el siguiente epígrafe, con su jurisprudencia el TJ progresivamente va delimitando el contenido y alcance que presenta el derecho de asilo en el DUE, de conformidad con la Convención de 1951 y según se prevé en el art. 18 de la CDFUE.

No obstante, también se debe advertir que no está en absoluto garantizado que las sentencias del TJ en Comisión/Hungría y en otros asuntos como $M N F$ y otros, aseguren la efectiva aplicación de la normativa del SECA en

67 Apdos. 297-301.

68 Apdos. 303-313. 
favor de los miles de potenciales solicitantes de protección internacional que llegaron a territorio húngaro durante el período 2015-2020. A fecha de hoy, es muy probable que la vulneración de esta normativa por Hungría en miles de casos no sea reparada debidamente. Entre otras razones porque buena parte de esos potenciales solicitantes de protección internacional han sido expulsados o se han visto obligados a abandonar Hungría ante la imposibilidad de solicitar y obtener protección internacional en este Estado miembro.

A este respecto, conviene señalar que en Comisión/Hungría el TJ rechaza la inadmisión de este asunto que Hungría plantea por el cierre de las zonas de tránsito, siguiendo reiterada jurisprudencia del TJ, según la cual se mantiene el interés de la Comisión en interponer un recurso incluso cuando la infracción imputada se haya eliminado con posterioridad al plazo fijado en el dictamen motivado ${ }^{69}$. El AG también mantiene esta misma postura, y destaca que aunque cuando se dicte la sentencia el incumplimiento del DUE puede haber cesado, el objeto del recurso puede consistir en establecer las bases de la responsabilidad en que haya podido incurrir un Estado miembro como consecuencia de su incumplimiento frente a aquellos para los que se deriven derechos de dicho incumplimiento ${ }^{70}$. Es decir, con carácter general la sentencia del TJ en Comisión/Hungría abre las puertas para que los particulares puedan exigir ante los tribunales internos húngaros una reparación patrimonial por los daños causados por el incumplimiento del DUE protagonizado por las autoridades de Hungría, según ha sido declarado por el TJ en esta sentencia ${ }^{71}$.

69 El TJ rechaza la alegación que plantea el Gobierno húngaro relativa a que, a mediados de 2020, en cumplimiento de la sentencia en FMS, se cerraron las dos zonas de tránsito, y por tanto desde esa fecha ya no se vulneran las normas sobre internamiento de solicitantes de protección internacional, por lo que el motivo de incumplimiento relativo a esta cuestión deja de tener objeto. Según el TJ la existencia del incumplimiento debe apreciarse en función de la situación en la que se encontraba el Estado miembro, y algo más en concreto de la legislación interna que estaba en vigor en dicho Estado al finalizar el plazo fijado en el dictamen motivado remitido por la Comisión Europea, el 8 de febrero de 2018: apdos. 68-70 y 156.

70 Conclusiones, puntos 34-35.

71 Para un estudio reciente de este tema desde la abundante práctica protagonizada por España, véase Alonso y Martín (2020: 25 y ss.). A este respecto, está pendiente de respuesta el recurso por incumplimiento C-278/20 (DO C 271, de 17 de agosto de 2020), en el que la Comisión pide que se declare que al adoptar determinados preceptos de la Ley 39/2015 (BOE 236, de 2 de octubre de 2015), el Reino de España ha incumplido las obligaciones que le incumben en virtud de los principios de efectividad y de equivalencia como límites a la autonomía de que gozan los Estados miembros 
Pero en este caso está en juego la efectiva aplicación de la normativa del SECA en beneficio de miles de nacionales de terceros Estados o de apátridas, potenciales solicitantes de protección internacional, que como ya se ha señalado en su gran mayoría han sido expulsados o se han visto obligados a abandonar Hungría durante este período 2015-202072. No parece nada probable que este grupo de personas tenga la posibilidad real de presentar una demanda con visos de éxito ante los tribunales húngaros, por más que dispongan en su favor de los fundamentos jurídicos que les ofrece Comisión/Hungría ${ }^{73}$.

Las vulneraciones de las normas que conforman el SECA por parte de Hungría pueden tener, además, un efecto perverso para otros Estados miembros y para la coherencia del propio SECA. Dadas las evidentes deficiencias sistemáticas que presenta la aplicación del derecho de asilo en este Estado, en cumplimiento del art. 3.2 del Reglamento de Dublín ${ }^{74}$, el resto de Estados miembros no podrán enviar a Hungría a aquellas personas que entraron en la UE por territorio húngaro para que las autoridades húngaras

cuando establecen las condiciones de fondo y de forma que rigen su responsabilidad por daños causados a los particulares en violación del derecho de la Unión.

72 Más en concreto, se ha destacado que de unos 65000 nacionales sirios que, en 2015, tras huir del conflicto armado que estaba asolando a su país, trataron de solicitar protección internacional en Hungría, las autoridades húngaras solo concedieron el estatuto de refugiado a diecinueve de ellos y protección subsidiaria a otros 140: Armstrong (2019: 80).

73 Como se ha dicho, los tribunales no pueden resolver todos los problemas que afectan a la aplicación de las normas del SECA, porque muchas de las violaciones de tales normas no alcanzan a plantearse en sede judicial, ya que "Refugees usually posses neither the knowledge nor the resources to seek judicial protection»: Goldner Lang (2020: 45).

74 «Cuando sea imposible trasladar a un solicitante al Estado miembro que se haya designado en primer lugar como responsable, debido a que hay razones fundadas para temer que existen deficiencias sistemáticas en el procedimiento de asilo y en las condiciones de acogida en ese Estado miembro que implican un peligro de trato inhumano o degradante, en el sentido del artículo 4 de la Carta de los Derechos Fundamentales de la Unión Europea, el Estado miembro encargado de la determinación seguirá examinando los criterios fijados en el capítulo III para decidir si otro Estado miembro puede ser designado como responsable. Cuando el traslado no pueda hacerse, con arreglo al presente apartado, al Estado miembro designado sobre la base de los criterios fijados en el capítulo III o al primer Estado miembro en el que se presentó la solicitud, el Estado miembro encargado de la determinación pasará a ser el Estado miembro responsable». 
sean las responsables de las solicitudes de asilo de tales personas; el citado art. 3.2 así lo prohíbe (Fernández, Halcón y Serrano, 2016: 118-119)75.

En este punto se debe traer a colación la amplia discrecionalidad de la que disfruta la Comisión con relación a todo el procedimiento por incumplimiento, reconocida por el TJ en su jurisprudencia ${ }^{76}$, incluso en supuestos en los que la Comisión decide demandar solamente a una parte de los Estados miembros que están incumpliendo una misma normativa ${ }^{77}$. Dentro de esta amplia discrecionalidad, con carácter general la Comisión concibe el procedimiento por incumplimiento como el último recurso para garantizar el cumplimiento del DUE, una vez resultan infructuosas las actuaciones basadas en el diálogo y la cooperación con las autoridades estatales. De hecho, en Comisión/Hungría, aunque los incumplimientos de las normas del SECA se inician en 2015, la Comisión interpone el recurso por incumplimiento el 21

75 Como el TJ ha reconocido ante las deficiencias sistémicas en el procedimiento de asilo en el caso de Grecia. Véanse las sentencias de 21 de diciembre de 2011, N.S., C-411/10 y C-493/10, EU:C:2011:865; de 14 de noviembre de 2013, Bundesrespublik, C-4/11, EU:C:2013:740; y de 10 de diciembre de 2013, Sahmso, C-394/12, EU:C:2013:813. También la Sentencia de 19 de marzo de 2019, Bashar, C-297/17, C-318/17, C-319/17 y C-438/17, EU:C:2019:219, en la que el TJ mantiene que la aplicación del Reglamento de Dublín debe respetar el art. 4 de la CDFUE, en el que se prohíben los tratos inhumanos o degradantes, incluso en un supuesto en el que el solicitante de protección internacional haya obtenido previamente la protección subsidiaria en un Estado miembro. Y la Sentencia de 19 de marzo de 2019, Jawo, C-163/17, EU:C:2019:218, en la que el TJ añade que se debe tener en cuenta también la situación en la que se encontrará el solicitante de asilo en el Estado miembro al que es trasladado, en este supuesto Italia, incluso una vez concedida la protección internacional; si corre el riesgo de encontrarse en una situación de indigencia — «de privación material extrema»—, su traslado desde Alemania sería contrario al art. 4 de la CDFUE.

76 «De reiterada jurisprudencia del Tribunal de Justicia se desprende que la Comisión dispone de una facultad de apreciación para decidir sobre la oportunidad de actuar contra un Estado miembro, especificar las disposiciones que este haya podido infringir y elegir el momento en que inicia contra él el procedimiento por incumplimiento, sin que puedan afectar a la admisibilidad del recurso las consideraciones que determinen dicha decisión»: Comisión/Polonia, Hungría y República Checa, apdo. 75.

77 Como reconoce el TJ en Comisión/Polonia, Hungría y República Checa, en el que la Comisión no demanda a todos los Estados miembros que están incumpliendo la misma normativa, sino solo a aquellos que en su opinión protagonizan los incumplimientos más graves y persistentes, lo que no contraviene el margen de discrecionalidad que le permite el art. 258 TFUE: apdos. 81 y 82. 
de diciembre de 2018. Y la sentencia del TJ se dicta el 17 de diciembre de 2020.

En la práctica, como se demuestra en Comisión/Hungría, la actitud excesivamente contemporizadora que mantiene la Comisión permite que se prolonguen durante años situaciones en las que se dan incumplimientos muy claros del DUE hasta que finalmente se dicta una sentencia del TJ de carácter declarativo. Y ello sin que se le imponga ninguna suma a tanto alzado o multa coercitiva al Estado infractor, ya que para ello sería necesario iniciar un nuevo procedimiento ante el TJ, como se prevé en el art. 260.2 TFUE, en el supuesto de que dicho Estado no adoptara las medidas necesarias para la ejecución de la sentencia.

También cabe plantear si la Comisión debería haber solicitado al TJ la aplicación de una multa coercitiva o de una suma a tanto alzado a Hungría por el incumplimiento de determinadas disposiciones de las directivas 2008/115, 2013/32 y 2013/33, de conformidad con el art. 260.3 TFUE. En este precepto se prevé que el TJ imponga una multa coercitiva o una suma a tanto alzado al Estado que incumpla la obligación de informar a la Comisión sobre las medidas de transposición de una directiva adoptada conforme al procedimiento legislativo. Pero no parece que el supuesto que se contempla en este precepto incluya todos los asuntos en los que esté en juego la posible transposición incorrecta de una directiva ${ }^{78}$.

Con carácter general, en el contexto de los asuntos en los que la Comisión se decide a presentar un recurso por incumplimiento ante el TJ, suele recurrir con cuentagotas a los apdos. 2 y 3 del art. 260, con el objetivo de que se sancionen económicamente los incumplimientos del DUE. Ello explica que durante la última década el TJ haya dictado muy pocas sentencias en aplicación de estos dos apartados ${ }^{79}$.

Algo más en concreto, el balance de la labor de la Comisión como guardiana de las normas del SECA también confirma el amplio margen de discrecionalidad con el que esta institución hace uso de sus prerrogativas ante el TJ, y una postura claramente reacia a que se sancionen económicamente los

78 Sobre la aplicación del art. 260.3, véanse las sentencias de 8 de julio de 2019, Comisión/Bélgica, C-543/17, EU:C:2019:573; de 16 de julio de 2020, Comisión/Rumanía, C-549/18, EU:C:2020:563; y de 16 de julio de 2020, Comisión/Irlanda, C-550/18, EU:C:2020:564.

79 Según los informes anuales presentados por la Comisión, entre 2011 y 2019 se dictaron un total de veintisiete sentencias en aplicación del art. 260.2, y tres sentencias en aplicación del art. 260.3: Alonso y Martín (2020: 330). Más en concreto, en 2019 la Comisión presentó un único recurso en aplicación del art. 260.3, en concreto contra España en el asunto C-658/19 (European Commission, 2019: p. 27 de la Parte I). 
incumplimientos de los Estados miembros. Así, el 23 septiembre de 2015 la Comisión Europea hizo pública la apertura de 41 procedimientos de infracción como consecuencia de la incorrecta aplicación o de la transposición incompleta de algunos de los actos normativos que integran el SECA, que afectan nada menos que a diecinueve Estados, entre ellos España ${ }^{80}$. Todos estos procedimientos únicamente han dado lugar hasta la fecha a la presentación de dos recursos por incumplimiento ante el TJ: el que ha dado como resultado la sentencia en Comisión/Hungría, y el interpuesto también contra Hungría el 8 de noviembre de $2019^{81}$. La más que escasa presentación de recursos por incumplimiento por parte de la Comisión Europea ante el TJ, sin que hasta la fecha en ningún caso se haya recurrido a los apdos. 2 y 3 del art. 260, contrasta con las graves carencias que durante sobre todo los últimos cinco

80 Decisiones de la Comisión de 23 de septiembre de 2015, de infracción contra varios países de la UE por no aplicar plenamente la legislación del SECA. En concreto se trata de Bélgica, Bulgaria, República Checa, Alemania, Estonia, Grecia, España, Francia, Chipre, Letonia, Lituania, Luxemburgo, Hungría, Malta, Polonia, Rumanía, Eslovenia, Suecia y Austria. Para una valoración de la normativa española sobre el derecho de asilo y su conformidad con la normativa de la UE, véase Sánchez Sánchez (2016: 143 y ss.), en las que da cuenta de varios procedimientos por infracción iniciados por la Comisión Europea contra España, en concreto los números 2015/0413, por no comunicar la transposición de la Directiva 2013/32; 2015/0414, por no comunicar la transposición de la Directiva 2013/33, y 2014/0085, por no comunicar la transposición de la Directiva 2011/95.

81 En el asunto C-821/19. Según la Comisión Europea, con los cambios legislativos adoptados por el Parlamento húngaro en 2018, se restringe el círculo de personas que pueden beneficiarse del derecho de asilo, ya que se considera inadmisible la solicitud cuando el solicitante haya llegado al territorio de Hungría a través de un país en el que no haya estado expuesto a persecución ni al riesgo directo de ser perseguido. Además, en el Código Penal se tipifica como delito la actividad organizativa que tenga como finalidad posibilitar la incoación de procedimientos de asilo a personas que no sean perseguidas en su país de origen, en su país de residencia habitual o en otro país a través del cual llegaron a Hungría, por motivos de raza, nacionalidad, pertenencia a un grupo social determinado, religión u opiniones políticas, o que no tengan un temor fundado a ser perseguidas directamente. La Comisión Europea mantiene que la normativa húngara vulnera los arts. 33.2 de la Directiva 2013/32 al introducir un nuevo motivo de inadmisibilidad que no está expresamente previsto en esta directiva, y los arts. $8.2,12.1$ c) y 22.1 de la Directiva 2013/32/UE, así como el art. 10.4 de la Directiva 2013/33, a causa de la mencionada tipificación como delito de determinadas actividades dirigidas a posibilitar la incoación de procedimientos de asilo: DO C 19, de 20 de enero de 2020. 
años presenta la aplicación de la normativa que forma el SECA en algunos Estados miembros como, entre otros, es el caso de Grecia ${ }^{82}$.

Desde luego, Hungría es uno de los Estados que se sitúa en cabeza en este lamentable orden de prelación de incumplimientos del DUE relativo al SECA. Además de los dos recursos por incumplimiento presentados ante el TJ que se acaban de mencionar, también se ha citado la sentencia en Comisión/ Polonia y otros, en la que se llega a la conclusión de que las autoridades húngaras no han permitido que se reubique en Hungría a ninguno [sic] de los 1294 posibles solicitantes de protección internacional que le correspondía aceptar ${ }^{83}$. Basta añadir para confirmar esta conclusión que el 10 de octubre de 2019 la Comisión Europea hizo público que había remitido su dictamen motivado al Gobierno húngaro, en el que califica de vulneración del art. 16 de la Directiva de retorno y del art. 4 de la CDFUE, la práctica seguida por las autoridades húngaras consistente en internar sin darles comida durante varios días a los solicitantes de protección internacional en las mencionadas zonas de tránsito en la frontera entre Hungría y Serbia ${ }^{84}$. La gravedad de los hechos descritos explica que el TEDH haya adoptado medidas cautelares a este respecto en más de veinte demandas presentadas contra Hungría, en aplicación del art. 39 de su reglamento ${ }^{85}$.

Con relación a la práctica que mantiene la Comisión Europea, se debe tener en cuenta, además, que, como es sabido, los particulares no pueden presentar un recurso de incumplimiento ante el TJ, y solo pueden presentar un recurso por anulación si se cumplen las estrictas condiciones que se prevén

82 No hace mucho se llegaba a la siguiente conclusión: «in Greece, a country still struggling to disengage from the financial crisis, migrants face chaotic registration procedures, serious obstacles to applying for asylum, and inadequate reception conditions with lack of food and healthcare facilities»: Wauters y Cogolati (2020: 127).

$84 \mathrm{IP} / 19 / 5994$.

85 La Comisaria de Derechos Humanos del Consejo de Europa ha denunciado públicamente a Hungría por estos hechos: Commissioner (2019: 4): "The Commissioner is alarmed that many asylum seekers detained in the transit zones under an alien policing procedure have been deprived of food during their detention and calls on the authorities to put an immediate end to such inhumane treatment». Entre otros casos, en E.X. c. Hungary (app. 15763/20), el 3 de abril de 2020 el TEDH dicta medidas cautelares en favor del solicitante, internado por las autoridades húngaras en una de las zonas de tránsito sin proporcionarle comida durante cinco días. Con relación a otros casos, véase el estudio que ofrece el European Council of Refugees and Exiles, en el que califica la conducta de las autoridades húngaras como un patrón de «starvation tactics», en: https://bit.ly/3cekTmk. 
en el art. 263 TFUE $^{86}$. Asimismo, se debe añadir que, al menos sobre el papel, de conformidad con el art. 259 del TFUE, cualquiera de los Estados miembros puede presentar un recurso por incumplimiento ante el TJUE contra el Estado que esté vulnerando las normas que integran el SECA. Pero a fecha de hoy la aplicación del art. 259 no deja de ser una hipótesis de laboratorio: no existe ningún precedente, y no parece nada probable que en los próximos años los Estados miembros se vayan a denunciar entre sí por no cumplir las normas del SECA. Buena parte de ellos las están incumpliendo en mayor o menor medida, como así lo demuestra la apertura por la Comisión Europea de un buen número de procedimientos por infracción.

En esta misma dirección, la solicitud presentada por el PE para que se active el procedimiento preventivo previsto en el art. 7.1 del TUE contra Hungría, entre otros motivos a causa de la situación en la que se encuentran los inmigrantes y refugiados en ese Estado miembro ${ }^{87}$, no ha recibido ninguna respuesta por parte del Consejo, salvo la celebración de algunas audiencias con las autoridades de Hungría, calificadas con toda razón de anodinas. Hasta el punto de que el Consejo no ha permitido al PE, la institución impulsora de la aplicación del art. 7.1, la participación en las mismas (Cortés Marín, 2020: 480-485).

A este respecto, falta por comprobar si el recientemente aprobado Reglamento (UE, Euratom) 2020/2092 del PE y del Consejo, de 16 de diciembre de 2020, sobre un régimen general de condicionalidad para la protección del

86 Si bien los particulares sí pueden presentar una demanda ante TEDH, como se acaba de citar con relación a los casos en los que el TEDH ha adoptado medidas cautelares. Están pendientes de respuesta ante el TEDH las demandas en las que se defiende que la expulsión por parte de las autoridades húngaras de nacionales de terceros países contraviene el CEDH, presentadas el 10 de febrero de 2017, Khurram v. Hungary (app. 12635/17), y el 3 de marzo de 2017, H.K. v. Hungary (app. 18531). Como se puede comprobar en atención a las fechas en las que se presentan las demandas, muy probablemente las sentencias que se dicten en estos casos, de ser favorables a los particulares demandantes, tampoco les van a asegurar el efectivo respeto de los derechos humanos incumplidos por las autoridades húngaras; pero al menos podrán obtener una satisfacción equitativa en forma de suma de dinero.

87 Resolución del PE, de 12 de septiembre de 2018, sobre una propuesta en la que solicita al Consejo que, de conformidad con el art. 7, apdo. 1, del TUE, constate la existencia de un riesgo claro de violación grave por parte de Hungría de los valores en que se fundamenta la Unión: P8_TA (2018) 0340. Según el PE, entre los principales motivos de preocupación con relación al respeto de los valores del art. 2 TUE en Hungría se encuentran: «l) los derechos fundamentales de los migrantes, solicitantes de asilo y refugiados» (cursiva añadida). 
presupuesto de la Unión ${ }^{88}$, permitirá la adopción de «medidas adecuadas» contra el Estado que incumpla los principios del Estado de derecho. Aunque el hecho de que la decisión sobre la adopción de tales medidas corresponda al Consejo, y que esta misma institución pueda modificar la propuesta de la Comisión por mayoría cualificada (art. 6.10), no augura un futuro muy prometedor sobre la efectividad de este nuevo mecanismo de control y sanción del cumplimiento de los principios del Estado de derecho. Más aún si se tienen en cuenta todas las salvaguardas consensuadas en el Consejo Europeo como condiciones para su aplicación ${ }^{89}$.

En definitiva, el balance que ofrece la aplicación de la normativa del SECA no es en absoluto satisfactorio, como así lo demuestran los hechos que son juzgados en Comisión/Hungría. Como ha declarado el TJ, durante unos cinco años las autoridades húngaras han impedido que miles de nacionales de terceros Estados o de apátridas que han llegado a su territorio puedan solicitar y en su caso obtener protección internacional. Con la única «sanción» que constituye la declaración de la infracción del DUE que han protagonizado las autoridades de este Estado mediante una sentencia de la Gran Sala del TJ - sin que se concreten las medidas que deben adoptar las autoridades húngaras para conseguir el cese y la reparación del ilícito que han cometido $^{90}$ _, y la condena en $\operatorname{costas}^{91}$. Sin que se haya impuesto a Hungría una suma a tanto alzado o una multa coercitiva. Y sin que de hecho la gran mayoría de los particulares puedan obtener una reparación patrimonial por la vulneración que han sufrido del DUE.

Por todo ello, cabe proponer que ante incumplimientos del DUE tan flagrantes y persistentes como el protagonizado por las autoridades húngaras

88 DO L 433, de 22 de diciembre de 2020.

89 Véanse las Conclusiones del Consejo Europeo de 10-11 de diciembre de 2020, apdo. I.2, en https://bit.ly/3eh2Nmh.

90 Como es sabido, el recurso por incumplimiento está dirigido a obtener una declaración de incumplimiento, sin que el TJ pueda determinar las medidas que debe adoptar el Estado infractor para corregirlo: «esta jurisprudencia debe entenderse en el sentido de que, en los recursos por incumplimiento, la Comisión no puede solicitar al TJ más que declare la existencia del presunto incumplimiento a los efectos de que cese. De esta forma, la Comisión no puede, por ejemplo, solicitar al Tribunal de Justicia, en un recurso por incumplimiento, que conmine a un Estado miembro a adoptar un comportamiento concreto para conformarse al Derecho de la Unión»: sentencia Comisión/ Polonia, Hungría y República Checa, apdo. 56.

91 Dado que el TJ estima en su totalidad cuatro de las pretensiones de la Comisión y una tercera parte de la quinta, condena a Hungría a cargar con sus propias costas y con cuatro quintas partes de las costas de la Comisión: apdo. 316. 
durante estos últimos cinco años la Comisión, en primer lugar, sea mucho más diligente y resolutiva a la hora de iniciar un procedimiento por infracción y de presentar un recurso por incumplimiento ante el TJ. Como se ha comprobado, en Comisión/Hungría la Comisión ha tardado nada menos que tres años en presentar dicho recurso. En segundo lugar, la Comisión debería acompañar una solicitud de medidas provisionales al recurso por incumplimiento presentado ante el TJ, con las que se ordene la suspensión de la aplicación de la normativa interna que contradice claramente el DUE, como así era manifiesto en Comisión/Hungría. Además, la Comisión debería pedir al TJ que en caso de que el Estado miembro no cumpla con la medida cautelar, se le imponga una multa coercitiva, a razón de un tanto por cada día que persista el incumplimiento de la medida cautelar. Ya existen precedentes a este respecto. En aplicación del art. 279 TFUE, el TJ atendió la solicitud de medidas provisionales presentada por la Comisión en Comisión/Polonia (Bosque de Bialowieza), y apercibió a Polonia con la imposición de una multa coercitiva de al menos 100000 euros al día si no detenía la tala de árboles del mencionado bosque, en contravención de la Directiva de hábitats ${ }^{92}$.

Mutatis mutandis, en Comisión/Hungría, la Comisión también podría haber solicitado al TJ medidas provisionales y la imposición de una multa coercitiva, para detener la aplicación de la normativa interna húngara que vulneraba las tres mencionadas directivas respecto de miles de potenciales solicitantes de protección internacional que se encontraban en su territorio, y para así evitar que sufrieran un daño grave e irreparable. Como se ha demostrado que han soportado la gran mayoría de ellos, al ser expulsados de Hungría o verse obligados a abandonar el territorio húngaro sin poder solicitar protección internacional, en clara contravención del DUE. Muy probablemente, hubiera sido una vía efectiva para impedir que el incumplimiento del DUE por parte de Hungría se prolongara durante varios años, y, además, un aviso para navegantes muy contundente para otros Estados miembros que tampoco cumplen la normativa sobre el SECA y, en última instancia, están poniendo en peligro el respeto de los principios sobre que los que se asienta el proceso de integración europea regulados en el art. $2 \mathrm{TUE}^{93}$.

92 Auto de 20 de noviembre de 2017, Comisión/Polonia (Bosque de Bialowieza), C-441/17 R, EU:C:2017:877.

93 En su auto en Comisión/Polonia (Bosque de Biolowieza), el TJ afirma que «el hecho de hacer respetar por un Estado miembro las medidas provisionales adoptadas por el juez que conoce de las medidas provisionales, previendo la imposición de una multa coercitiva en caso de incumplimiento de estas, tiene por objeto garantizar la aplicación efectiva del Derecho de la Unión, la cual es inherente al valor del Estado de Derecho consagrado en el artículo 2 TUE y en el que se basa la Unión»: apdo. 102. 


\section{CONSIDERACIONES FINALES}

La sentencia dictada por el TJ en Comisión/Hungría confirma que los desarrollos jurisprudenciales en la interpretación y aplicación de las normas del SECA han contribuido «a labrar un estatuto de la protección internacional indiscutiblemente autónomo — enmarcado en las reglas y principios de la UE y desbordando con creces las ralas obligaciones jurídico internacionales en materia de refugio-, pero crecientemente garantista» (González Vega, 2017: 74). A diferencia de otros asuntos en los que se pedía al TJ una interpretación de las normas del SECA que iba más allá de su tenor literal ${ }^{94}$, en Comisión/Hungría el Tribunal de Luxemburgo certifica judicialmente que las autoridades húngaras han vulnerado de forma manifiesta y prolongada en el tiempo tales normas con relación a miles de nacionales de terceros países que llegaron a su territorio durante el período 2015-2020.

Aunque la normativa del SECA se concibe como una normativa de mínimos, que permite a los Estados miembros un considerable margen de discrecionalidad sobre temas muy relevantes del régimen jurídico que se diseña de protección internacional (Sánchez Legido, 2018: 204-205), la sentencia del TJ en Comisión/Hungría deja bien claro que los Estados miembros deben cumplir con las obligaciones que se derivan de dicha normativa y no pueden infringirla a su antojo, incluso en situaciones en las que soporten cierta presión migratoria en forma de llegada a su territorio de miles de potenciales solicitantes de protección internacional. El TJ se muestra contundente para

94 Por ejemplo, en su Sentencia de 7 de marzo de 2017, X y X/Bélgica, C-638/16 PPU, EU:C:2017:173, el TJ niega que el DUE obligue a los Estados miembros a conceder un visado humanitario solicitado en embajadas y consulados, con el objetivo de pedir protección internacional en el Estado miembro obligado a conceder tal visado humanitario. El TJ se muestra contundente al afirmar que «resulta del artículo 3, apartados 1 y 2, de la Directiva 2013/32 que esta Directiva es aplicable a las solicitudes de protección internacional presentadas en el territorio, incluida la frontera, en las aguas territoriales o en las zonas de tránsito de los Estados miembros, pero no a las solicitudes de asilo diplomático o territorial presentadas en las representaciones de los Estados miembros. Asimismo, de los artículos 1 y 3 del Reglamento n. ${ }^{\circ}$ 604/2013 se desprende que este Reglamento sólo obliga a los Estados miembros a examinar cualquier solicitud de protección internacional presentada en el territorio de un Estado miembro, incluida la frontera, o en las zonas de tránsito, y que los procedimientos establecidos en ese Reglamento se aplican únicamente a tales solicitudes de protección internacional»: apdo. 49. Para una crítica de esta sentencia, y la valoración de las propuestas que en el PE se han planteado sobre este tema, véanse Morgades Gil, (2019: 276 y ss.); Sánchez Legido (2017: 457 y ss.). 
llegar a la conclusión de que las autoridades húngaras han vulnerado de forma flagrante y durante varios años la normativa de la UE que regula las garantías y procedimientos que deben cumplir los Estados miembros para permitir que se presente una solicitud de protección internacional; para internar a los solicitantes de protección internacional; para expulsar a un nacional de un tercer país; y para permitir a los solicitantes de protección internacional que presenten un recurso con efecto suspensivo contra la decisión denegatoria de su solicitud.

Como ya se ha señalado, el desarrollo del proceso de integración europea ha conllevado la adopción de una normativa, la que integra el SECA, con la que se pretende asegurar el cumplimiento lo más homogéneo que sea posible de las obligaciones internacionales asumidas por todos los Estados miembros, en virtud de la Convención de 1951 (art. 78.1 TFUE). En este sentido, conviene destacar que al haber sido regulada mediante normas del DUE, como es obvio el cumplimiento de tales normas por los Estados miembros podrá ser objeto del control jurisdiccional por parte del TJ, a diferencia de lo establecido en el marco jurídico general de la Convención de 1951, en el que no se prevé la competencia de ningún tribunal internacional que se encargue de velar por el respeto de este tratado internacional por sus Estados parte (González Vega, 2017: 36; Martín y Pérez de Nanclares, 2019: 165).

En efecto, la competencia que asume el TJ para garantizar una interpretación y aplicación uniforme del DUE en este ámbito, como si se tratara de un tribunal internacional de asilo, resulta muy relevante, dado que puede fiscalizar el cumplimiento de las normas que forman el SECA por parte de todos los Estados miembros. La sentencia en Comisión/Hungría constituye un buen ejemplo a este respecto. Otras sentencias, en el ámbito de su competencia prejudicial, también lo son, como, entre otras, FMS y otros.

La importancia de esta jurisprudencia es indudable, ya que los pronunciamientos del TJ son de obligado cumplimiento para las autoridades de los veintisiete Estados miembros, tanto legislativas como judiciales y administrativas. Se puede afirmar, por tanto, que las sentencias del Tribunal de Luxemburgo despliegan su autoridad erga omnes, en toda la UE, debiendo ser tenidas en cuenta por las autoridades estatales a la hora de cumplir la normativa que integra el SECA. Desde este punto de vista, la jurisprudencia del TJ contribuye a armonizar la aplicación de la normativa del SECA por parte de los veintisiete Estados miembros de la UE, y por esta vía concreta el contenido y alcance del derecho de asilo previsto en el art. 18 de la CDFUE. $\mathrm{El}$ análisis de la jurisprudencia del TJ confirma que el desarrollo del proceso de integración europea y de su ordenamiento jurídico ha aportado mayor seguridad jurídica en favor de los solicitantes de protección internacional que 
llegan al territorio de un Estado miembro de la UE, en el marco del subsistema de DI particular que constituye la UE (Soler García, 2019: 481).

Pero al mismo tiempo, la jurisprudencia dictada por el TJ durante los últimos años también pone en evidencia que algunos Estados miembros, $\mathrm{y}$ entre ellos destaca el caso de Hungría, vienen incumpliendo, con casi total impunidad, buena parte de las normas que conforman el SECA. Hasta el punto de convertir en ilusoria la efectiva aplicación de tales normas para miles de potenciales solicitantes de protección internacional que han llegado a territorio húngaro. La Sentencia del TJ en Comisión/Hungría así lo ha constatado.

Lo que pone de manifiesto que tanto el panorama actual, como las perspectivas de futuro con relación a la efectiva aplicación de las normas del DUE que forman el SECA, se presentan con muchas dudas e incertidumbres. La presión migratoria que vienen soportando algunos Estados miembros, junto con el contexto de política interna por el que atraviesan algunos de ellos, ha provocado que durante estos últimos años se estén desgajando las costuras sobre las que se asienta toda la estructura normativa creada en torno al SECA. En esta misma dirección, resulta bastante incierto si las propuestas de reforma del SECA presentadas por la Comisión en 2016 y en 2020 llegarán a buen puerto ${ }^{95}$.

95 Entre otras cuestiones, resulta difícil predecir si en los próximos años será posible modificar, y en qué sentido y con qué alcance, el Reglamento 604/2013 (conocido como Reglamento de Dublín III), para establecer nuevos criterios de determinación del Estado responsable de las solicitudes de asilo y algún mecanismo de reparto de solicitudes entre los Estados miembros, que concrete la aplicación del principio de solidaridad y de reparto equitativo de la responsabilidad entre los Estados miembros, también en el aspecto financiero, como se preceptúa en el art. 78 TFUE, para evitar que los Estados miembros con fronteras exteriores tengan que hacer frente a la mayor parte de las solicitudes de protección internacional. Véase la citada propuesta de la Comisión (COM2020 610 final: 20 y ss. y arts. 45 y ss. de la propuesta de Reglamento), con la que, aunque por una parte se propugna mantener fundamentalmente los mismos criterios de determinación del Estado responsable de las solicitudes de asilo, por otra se defiende un nuevo mecanismo de solidaridad, presentado con un «diseño flexible», con el que se prevén contribuciones obligatorias por parte de los Estados miembros consistentes en reubicar migrantes o bien en patrocinar retornos, además de la posibilidad de contribuir con medidas dirigidas a reforzar la capacidad de los Estados miembros en el ámbito del asilo, la acogida, el retorno y la acción exterior. Todo ello de conformidad con una clave de reparto basada al $50 \%$ en el PIB y al $50 \%$ en la población de cada Estado miembro. Véanse Abrisketa Uriarte (2019: 263 y ss.); Sánchez Legido (2018: 212-215). 
Todo apunta a que se abren dos posibles escenarios. O bien, en aras de alcanzar el consenso entre los Estados miembros, en el Consejo se modifican a la baja las propuestas de la Comisión, desde la perspectiva de los derechos y garantías procedimentales de los solicitantes de protección internacional; siempre, claro está, que el PE así lo acepte. O bien se recurre a la cooperación reforzada, con lo cual se permitirá que un grupo de Estados puedan continuar adelante con la «comunitarización» de este sector normativo, en beneficio de los solicitantes de protección internacional. De hecho, esta segunda opción ya se viene poniendo en práctica durante las últimas décadas, si bien con la fórmula jurídica de añadir Protocolos al TUE y al TFUE, con los que se permite que Irlanda (hasta hace poco, también el Reino Unido) y Dinamarca no participen y por tanto no estén vinculados por la normativa relativa al SECA $^{96}$. Aunque la incógnita que ahora mismo presenta esta segunda opción es determinar cuántos Estados miembros estarán dispuestos a continuar los avances del proceso de integración europea en este ámbito, y en qué medida ${ }^{97}$.

En todo este contexto, como se ha comprobado en los anteriores epígrafes, el original y desarrollado equilibrio interinstitucional diseñado en los tratados constitutivos en última instancia puede conducir a situaciones en las que no se garantiza la efectiva aplicación del DUE. Dado que los Estados miembros son muy reacios a demandarse entre sí mediante el recurso por incumplimiento, y los particulares disponen de una muy limitada legitimidad procesal para defender sus derechos ante el TJ, la Comisión se encuentra en una posición extremadamente compleja. Porque, por una parte, le corresponde la vigilancia del cumplimiento de las normas del SECA por los Estados miembros (art. 17.1 TUE). Pero, por otra, en el ejercicio de su derecho de iniciativa normativa (art. 17.2 TUE), también debe convencer a esos mismos Estados miembros, contra los que en algunos casos inicia procedimientos por infracción del DUE, de la necesaria reforma de las normas del SECA; normas

96 Se trata del Protocolo número 21 sobre la posición del Reino Unido y de Irlanda respeto del espacio de libertad, seguridad y justicia, y del Protocolo número 22 sobre la posición de Dinamarca. Aunque tanto Irlanda como Dinamarca pueden voluntariamente quedar vinculados por la normativa del SECA, y de hecho así ha ocurrido con relación a algunos de los instrumentos normativos. Por ejemplo, Irlanda notificó su intención de participar en la adopción y aplicación del Reglamento de Dublín, y Dinamarca celebró un acuerdo internacional con la UE en 2006 (DO L 66, de 8 de marzo de 2006) mediante el que aplica el citado Reglamento: COM (2020) 610 final, pp. 8-9.

97 Con cierto escepticismo, se advertía no hace mucho lo siguiente: «Más de uno podría pensar incluso que en la actualidad no sería nada sencillo acordar una Convención como la que se adoptó en 1951»: Martín y Pérez de Nanclares (2019: 172). 
que precisamente algunos de ellos están incumpliendo durante los últimos años.

Lo que en alguna medida explica, que no justifica, la postura excesivamente contemplativa que la Comisión viene manteniendo ante tales incumplimientos de las normas del SECA y, más en particular, su criticable falta de iniciativa para que se sancione económicamente a los Estados que los están protagonizando, como es el caso palmario de Hungría. En tales casos, la Comisión Europea debería mostrarse mucho más diligente y resolutiva a la hora de acudir al TJ y solicitar la imposición de una sanción económica. Porque lo que está juego es la efectiva aplicación de un sector normativo del DUE que sin duda debe ser incluido dentro del contenido de los valores del art. 2 del TUE.

No es de extrañar, en este sentido, que en el Nuevo Pacto sobre Migración y Asilo no se incluya ninguna referencia a posibles medidas o actuaciones judiciales, incluida la solicitud de adopción de sanciones económicas por parte del TJ, aplicables en el supuesto de que los Estados miembros incumplan las normas que lo conforman ${ }^{98}$. La Comisión pretende así construir un escenario de futuro un tanto idílico, en el que las mejoradas normas del SECA que propone se van a respetar por todos los Estados miembros, sin que sea necesario hacer mención expresa de los mecanismos aplicables para responder ante su incumplimiento. Escenario de futuro que por desgracia no se corresponde con la realidad de los últimos años.

Eso sí, siempre nos quedará Luxemburgo, el control jurisdiccional del TJ, como es obvio en el marco del sistema de recursos y competencias que le corresponden según los tratados constitutivos, para tratar de poner orden en este convulso e intrincado escenario a través de su labor judicial. En última instancia para dejar bien claro, como así lo ha hecho en Comisión/Hungría, que, a pesar de la creciente heterogeneidad que afecta al proceso de integración

98 Se debe recordar, a este respecto, que en la propuesta de Reglamento por el que se establece la Agencia de Asilo de la UE (COM2016 271 final) se regula (arts. 13 y ss.) un mecanismo de supervisión y evaluación de los sistemas de acogida y asilo, cuya puesta en práctica pueda dar lugar a que la Comisión, mediante un acto de ejecución, obligue a un Estado miembro a aceptar el apoyo de la Agencia de Asilo, incluido el despliegue en su territorio de los denominados «expertos de la reserva de intervención en materia de asilo», así como del personal de la propia Agencia (art. 22.3). Pero en septiembre de 2018 la Comisión presenta la propuesta modificada de Reglamento relativo a la Agencia de Asilo de la UE, en la que, tras las negociaciones mantenidas entre el PE y el Consejo sobre su propuesta, se asume que la competencia para adoptar dicho acto de ejecución corresponde al Consejo y no a la Comisión: COM2018 633 final: 5-6. 
europea sobre todo durante las dos últimas décadas, en la UE están vigentes y deben ser efectivamente respetados los valores sobre los que se asienta esta organización internacional y en definitiva vertebran el consensus sobre el que descansa este sistema subregional de $\mathrm{DI}^{99}$ : la democracia, el Estado de derecho y el respeto de los derechos humanos (art. 2 TUE).

\section{Bibliografía}

Abrisketa Uriarte, J. (2019). The Reform of the Dublin III Regulation: How to Build or Not to Build Further Enforcing Mechanisms. The Spanish Yearbook of International Law, 23, 263-272. Disponible en: https://doi.org/10.17103/ sybil.23.16.

Alonso García, M. C. y Martín Delgado, I. (2020). La responsabilidad del Estado por el incumplimiento de las obligaciones normativas derivadas del Derecho de la Unión Europea: el caso de España. Madrid: Iustel.

Armstrong, A. B. (2019). Chutes and Ladders: Nonrefoulement and the Sisyphean Challenge of Seeking Asylum in Hungary. Columbia Human Rights Law Review, 50, 46-115.

Commissioner for Human Rights of the Council of Europe (2019). Report following her visit to Hungary from 4 to 8 February 2019. Estrasburgo: Consejo de Europa. Disponible en: https://bit.ly/2O6t3EE.

Cortés Marín, J. M. (2020). Sorteando los inconvenientes del artículo 7 TUE: el advenimiento del control jurisdiccional del Estado de derecho. Revista de Derecho Comunitario Europeo, 66, 473-517. Disponible en: https://doi.org/10.18042/ cepc/rdce.66.07.

European Commission (2019). Monitoring the Application of European Union Law. 2019 Annual Report. Bruselas: Comisión Europea.

Fernández Arribas, G., Halcón Lerdo de Tejada, A. y Serrano López, I. (2016). Violación del Derecho de solicitar asilo. La respuesta de Hungría a la crisis de los refugiados. Revista de Estudios Europeos, 67, 101-121.

Goldner Lang, I. (2020). No Solidarity without Loyalty: Why Do Member States Violate EU Migration and Asylum Law and What Can Be Done? European Journal of Migration and Law, 22, 39-59. Disponible en: https://doi. org/10.1163/15718166-12340068.

99 Entendido como «el conjunto de intereses y convicciones generales del grupo social internacional a los que se adhieren o aceptan los actores que lo forman, y que conduce necesariamente al cumplimiento probable de pautas habituales de comportamiento en el seno de dicho grupo»: Jiménez Piernas (1994: 95). 
González Vega, J. A. (2017). Mitos y mistificaciones: la Unión Europea y la protección internacional. Revista de Derecho Comunitario Europeo, 56, 27-75. Disponible en: https://doi.org/10.18042/cepc/rdce.56.02.

Jiménez Piernas, C. (1994). El concepto de Derecho Internacional Público (II). En M. Díez de Velasco. Instituciones de Derecho Internacional Público (pp. 89-113). Madrid: Tecnos.

Martín y Pérez de Nanclares, J. (2019). La insuficiente acción de la Unión Europea en materia de inmigración y asilo. En E. Garro Carrera y M. Landa Gorostiza (dirs.). Retos emergentes en los Derechos Humanos: ¿Garantias en peligro? (pp. 143-174). Valencia: Tirant Lo Blanch.

Martínez Alarcón, M. L. (2018). La Politica Europea de Protección Internacional. Navarra: Aranzadi.

Martínez Alarcón, M. L. (2019). Artículo 18. Derecho de asilo. En A. López Castillo (dir.). La Carta de Derechos Fundamentales de la Unión Europea. Diez años de Jurisprudencia (pp. 511-611). Valencia: Tirant Lo Blanch.

Morgades Gil, S. (2019). Humanitarian Visas and Discretionary Choices in the EU Policies on Visas and on International Protection. The Spanish Yearbook of International Law, 23, 273-284. Disponible en: https://doi.org/10.17103/ sybil.23.17.

Ortega Terol, J. M. (2018). Asilo y refugio y Tribunal de Justicia de la UE: notas para un réquiem. En A. Salinas de Frías y E. J. Martínez Pérez (dirs.). La Unión Europea y la protección de los derechos fundamentales (pp. 179-192). Valencia: Tirant Lo Blanch.

Ruiz Ramos, J. (2020). The Right to Liberty of Asylum-Seekers and the European Court of Human Rights in the Aftermath of the 2015 Refugee Crisis. Revista Electrónica de Estudios Internacionales, 39, 1-46. Disponible en: https://doi. org/10.17103/reei.39.10.

Sánchez Legido, A. (2017). El arriesgado acceso a la protección internacional en la Europa fortaleza: la batalla por el visado humanitario europeo. Revista de Derecho Comunitario Europeo, 57, 433-472. Disponible en: https://doi.org/10.18042/ cepc/rdce.57.02.

Sánchez Legido, A. (2018). Reconocimiento mutuo y crisis del sistema europeo común de asilo. En L. Arroyo Jiménez y A. Nieto Martín (dirs.). El reconocimiento mutuo en el derecho español y europeo (pp. 191-216). Madrid: Marcial Pons.

Sánchez Sánchez, Z. (2016). El derecho de asilo en la Unión Europea. En aras de un complejo equilibrio. Salamanca: Ratio Legis.

Soler García, C. (2019). Los límites a la expulsión de extranjeros ante el Tribunal Europeo de Derechos Humanos y el Tribunal de Justicia de la Unión Europea. Navarra: Aranzadi.

Sosa Navarro, M. (2020). Estado de Derecho, procedimiento por incumplimiento y el auge del autoritarismo en Hungría. A propósito de la Sentencia de 18 de junio de 2020 del TJUE sobre la Ley de Transparencia de las ONG. Revista General de Derecho Europeo, 52, 1-19. 
Wauters, E. y Cogolati, S. (2020). Crossing the Mediterranean Sea: EU Migration Policies and Human Rights. En V. Mitsilegas, V. Moreno-Lax y N. Vavoula (eds.). Securitising Asylum Flows (pp. 102-129). Leiden: Brill. Disponible en: https://doi.org/10.1163/9789004396814_007. 